\title{
Multilayered curcumin-loaded hydrogel microcarriers with antimicrobial function
}

\author{
Weronika Szczęsna ${ }^{1}$, Marta Tsirigotis-Maniecka ${ }^{1}{ }^{\text {, Lukasz Lamch }}{ }^{1}$, Lilianna Szyk-Warszyńska ${ }^{2}$, Ewa Zboińska ${ }^{3}$, \\ Piotr Warszyński2,", Kazimiera A. Wilk1,*
}

1 Department of Engineering and Technology of Chemical Processes, Faculty of Chemistry, Wrocław University of Science and Technology, 50-370 Wrocław, Poland; weronika.szczesna@pwr.edu.pl; marta.tsirigotis@pwr.edu.pl; lukasz.lamch@pwr.edu.pl; kazimiera.wilk@pwr.edu.pl

2 Jerzy Haber Institute of Catalysis and Surface Chemistry, Polish Academy of Sciences, 30-239 Kraków, Poland; Lilianna.szyk-warszynska@ikifp.edu.pl; Piotr.warszynski@ikifp.edu.pl

3 Department of Organic and Medicinal Chemistry, Faculty of Chemistry, Wrocław University of Science and Technology, 50-370 Wrocław, Poland; ewa.zboinska@pwr.edu.pl

* Correspondence: ncwarszy@cyf-kr.edu.pl; kazimiera.wilk@pwr.edu.pl

\begin{abstract}
The design of multifunctional microcarriers has attracted significant attention because they combine various functions within a single system. In this study, we developed a set of multilayered hydrogel microcarriers, which were first loaded with chemotherapeutic curcumin (CUR), then using the layer-by-layer (LbL) technique, coated through a polyelectrolyte shell consisting of chitosan (CHIT) or poly(allylamine hydrochloride) (PAH). As an outer layer with antimicrobial function, newly synthesised alkylene quaternary ammonium salt functionalised polyelectrolytes (A-QAS-PEs) were applied. For this purpose, poly(acrylic acid) (PAA) was decorated with different hydrophobic side chains ( $n$-hexane and $n$-dodecane side entities) and different degrees of substitution (m) of quaternary ammonium groups (abbreviated as PAA-C $(\mathrm{O}) \mathrm{O}-\left(\mathrm{CH}_{2}\right)_{\mathrm{n}}-\mathrm{N}^{+}\left(\mathrm{CH}_{3}\right)_{3}(\mathrm{~m})$; $\mathrm{n}=6,12 ; \mathrm{m}=8-14 \%$ ). The grafting approach of PAA with the alkylene quaternary ammonium salt moiety was performed under mild reaction conditions using Steglich esterification followed by quaternisation. The structure of antimicrobial decorated PAA was confirmed by ${ }^{1} \mathrm{H}$ NMR and FTIR, and the mean diameter of all multifunctional microparticles was characterised by SEM. The viscoelastic properties of the functional layers were studied using QCM-D. The release of CUR from the microcarriers was described using a hybrid model, i.e., a combination of first-order kinetics and the Korsmeyer-Peppas model. The antimicrobial activity of functionalised PAA and multilayered CUR-loaded hydrogel microcarriers with quaternary ammonium function was assessed against Staphylococcus aureus and Serratia marcescens by the agar diffusion assay method. Only a limited inhibition zone of PAA was observed, but in the case of both antimicrobial decorated PAA and the corresponding multilayered nanocarriers, the inhibitory activity increase was achieved against both strains of bacteria.
\end{abstract}

Keywords: multifunctional microcarriers; curcumin; decorated poly(acrylic acid); layer-by-layer (LbL) methodology; antimicrobial function

\section{Introduction}

In recent years, bacterial infections have become a major problem worldwide [1, 2]. Microbes are becoming more and more resistant to antibiotics and other antimicrobial agents. Thus, new biocidal strategies that do not require antibiotics should be developed and employed to treat infections caused by pathogenic microbes. One of the promising approaches for developing effective antimicrobial systems appears to be the surface functionalisation of carriers for drug delivery [3, 4]. Among these strategies, the layer-by-layer (LbL) technique is a versatile methodology to construct functional surfaces by alternate deposition of polycation and polyanion [5]. The LbL approach can be used to control the buildup of multilayer coatings of different architectures and functions on 
the nanometer scale $[6,7]$. The simplicity of LbL film formation enables one to design a variety of custom-designed materials with assumed antimicrobial features.

The design and fabrication of multifunctional hydrogel microparticles have recently attracted great interest because of their ability to put together various functions within a single entity [8]. One of the advantages of these microparticles is the ability to encapsulate numerous biologically active compounds that can provide targeted delivery of an encapsulated drug. Furthermore, multifunctional microcarriers can be easily coated with various functional films that incorporate additional functionality of the whole microsystem. In this way, we can design multifunctional microparticles in which the payload and the shell can act different roles. Microparticles that have multiple components and features can be easily adjusted to fulfil the requirements of desirable applications. In the fabrication of such microcarriers, the choice of appropriate material as a building block is crucial [9]. Biocompatible natural polymers such as sodium alginate (ALG) and chitosan (CHIT), as well as synthetic polymers such as poly(allylamine hydrochloride) (PAH) and poly(acrylic acid) (PAA), are considered as valuable building blocks for a broad range of drug delivery systems (DDS) that successfully provide the ability of the payload controlled release at the site of action.

Several natural and synthetic polyelectrolytes (PEs) with various functional moieties have been used as microparticle coatings. Polymers bearing positively charged groups are potential antimicrobial agents that can adhere to the negatively charged bacterial surface, causing structural disruption of the cell membrane. Thus, cationic PEs have emerged as promising compounds because of their antibacterial properties and biocompatibility [4, 10]. Among polyelectrolytes with various cationic moieties, quaternary ammonium compounds offer high efficacy in preventing the growth of bacteria [11-14]. The key factor providing the antimicrobial properties of the polymer is the degree of substitution of a functional group or alkyl side chain length. Therefore, the design of functionalised polyelectrolytes with the appropriate hydrophobic segments and cationic moieties is crucial for obtaining a high antibacterial efficiency. Multifunctional PEs can be synthesised using various approaches, such as direct copolymerisation or polycondensation, and multistep processes involving the preparation of the polymer backbone and then its functionalisation by coupling with various chemical moieties, quaternisation, hydrolysis, etc. [15-18]. In general, polyelectrolyte functionalisation, especially through decoration with short side groups, leads to obtaining products with a random structure [15]. This strategy often involves steps under mild conditions, such as Steglich esterification or amidation, to avoid degradation of the backbone [19, 20]. Polyelectrolytes with hydrophilic/hydrophobic side chains of various lengths with a suitable active moiety (e.g. ligand or antimicrobial group) attached to one of their ends are synthesised from suitable asymmetric precursors, like $\alpha, \omega$-substituted olefins or poly(ethylene oxides) [21]. The use of the mentioned derivatives avoids undesirable processes such as crosslinking or the formation of water-insoluble by-products (polymers with insufficient grafting). In addition, further end-groups reactions should be selective to avoid unnecessary reactions within the polymer backbone.

Literature reports show that nano- and microcapsules with functional coatings applied by the LbL technique are worth considering their application in antimicrobial therapy. The antibacterial properties of such structures can be adjusted by controlling the chemical composition and architecture of the capsules. For example, Ivanova et al. [4] designed polymer nanoparticles coated with cationic aminocellulose and anionic glycosaminoglycan - hyaluronic acid. Such nanosized materials showed strong antibacterial efficiency against both Gram-positive bacteria S. aureus and Gram-negative bacteria $E$. coli without affecting the viability of human fibroblast cells. In other work, researchers prepared microcapsules composed of alginate and polycyclodextrin that contain quaternary ammonium moieties as antimicrobial agents. The fabricated microparticles demonstrated an inhibitory effect against E. coli and S. aureus growth [22]. Therefore, the functionalisation of drug carriers with antimicrobial coatings using the LbL approach has great potential in various therapies. 
Curcumin (CUR) is a natural polyphenolic compound with promising health benefits due to its valuable biological activities such as antioxidant, anti-carcinogenic, antidiabetic, anti-proliferative, anti-infective and anti-inflammatory activities [23, 24]. CUR has attracted widespread attention in the treatment or prevention of numerous diseases such as cancer, liver, lung, autoimmune, neurological or cardiovascular diseases. For this reason, several studies have reported the encapsulation of CUR into microparticles for potential therapeutic application [24]. Our group has recently prepared and characterised hydrogel micro- and macroparticles based on ALG, CHIT, and gelatin to deliver curcumin to colon cancer cells [25]. As a continuation of our studies on rational drug delivery [26, 27], we designed, fabricated, and characterised multilayered hydrogel microcarriers, comprising the CUR-loaded core and the custom-designed LbL coatings, the latter formed by CHIT or PAH and - as the outer antimicrobial layer - alkylene quaternary ammonium salt functionalised poly(acrylic acid) (for abbreviations and structure details, see Table 1 in Section 2.1). Therefore, the above mentioned multifunctional microcarriers were composed of ALG, used as a core material, CHIT or PAH selected as the first layer, and a newly synthesised antimicrobial decorated poly(acrylic acid), deposited as the outer layer to provide the assumed functional coating. The morphology and composition of all fabricated microparticles were studied with scanning electron microscopy (SEM) and Fourier transform infrared (FTIR) spectroscopy, respectively. We assessed the thickness, mass, and viscoelastic properties of multilayer films during their buildup using the quartz crystal microbalance with dissipation (QCM-D) technique. In addition, the CUR kinetic release profiles and mechanisms were thoroughly analysed. Finally, we evaluated the influence of the coating features (i.e., thickness, type of layer, polyelectrolyte functionalisation) on the antimicrobial activity of the prepared microcarriers against the Gram-positive (Staphylococcus aureus) and Gram-negative (Serratia marcescens) bacterial strains. The acquired beneficial physicochemical and biological properties of the fabricated microparticles could allow designing systems to deliver pharmaceuticals (e.g., CUR) by oral or intravesical administration in various ways of treatments, including antimicrobial and cancer therapies [28, 29].

\section{Results and discussion}

Microcarriers with multilayer coatings built of modified polyelectrolytes of various functions constitute a promising group of DDS [30,31]. In addition, the rationally engineered polyelectrolytes such as alkylene quaternary ammonium salt functionalised polyelectrolytes (A-QAS-PEs) can be used as building blocks for multilayered microparticles. Using such polymers to impart new carriers properties via the LbL approach comprises a well-proven strategy that allows one to form a variety of tailor-made coatings exhibiting antimicrobial activity [32]. Thus, A-QAS-PEs may extend the conventional group of decorated PEs, opening new frontiers for their fabrication and characterising their unique properties.

\subsection{Design, grafting, and characterisation of poly(acrylic acid) containing alkylene quaternary ammonium groupings}

Antimicrobial actions of multilayer coatings can be achieved either by using PEs with intrinsic antimicrobial function [33] or by embedding in the film structure active components as metallic nanoparticles [34] or drug-containing nanocapsules [35, 36]. Functionalized PEs that show antimicrobial activities may be divided into three main groups: polymeric biocides, biocidal polymers, and biocide-releasing polymers [37]. For the preparation of nano- and microcarriers, showing intrinsic antimicrobial function, the second group of macromolecules, i.e. biocidal polymers, is particularly useful. The aforementioned function of the polymers is strictly connected with the fact that generally, microbial cells carry a negative net charge at the surface due to their membrane proteins, teichoic acids of Gram-positive bacteria, and negatively charged phospholipids at the outer membrane of Gram-negative bacteria. In this way, polycations (e.g. CHIT), if they have a proportionate amphiphilic character, can disrupt the outer and the cyto- 
plasmic membrane and cause cell lysis, resulting in its death. Numerous polymeric biocides possess cationic groups positioned along the polymer backbone, but there is also a very effective class of antimicrobial polymers with the biocidal end of the main or backside chain. Chemical moieties, mainly possessing quaternary ammonium salt and/or oxazoline group may play an antimicrobial role in very low concentrations, e.g. one end group per polymer. Coupling the mentioned group with a long alkyl chain may provide additional control of the whole molecule activity in the range of 3 orders of magnitude by the group distal to the biocide, a so-called satellite group [38]. The mentioned strategy for attaching a long alkyl chain and a labile moiety as the linking groups between the quaternary ammonium salt and the polymer backbone provides a novel synthesis approach of biocidal polymeric materials.

Alkylene quaternary ammonium salt decorated PAA was prepared in a two-step reaction (Scheme I). In the first step, poly(acrylic acid) modified with a bromine-terminated hydrophobic chain was synthesised under mild conditions by Steglich esterification with $\mathrm{N}, \mathrm{N}$-dicyclohexylcarbodiimide (DCC) as a coupling agent and 4-dimethylaminopyridine (DMAP) as a catalyst [19, 20]. Subsequently, bromine-terminated poly (acrylic acid) was converted to a quaternary ammonium salt by quaternisation with trimethylamine. Therefore, we decorated poly(acrylic acid) with various hydrophobic chains (that is, $n$-hexane and $n$-dodecane side entities) and different degrees of substitution $(\mathrm{m})$ for quaternary ammonium groups (abbreviated as PAA-C(O)O- $\left(\mathrm{CH}_{2}\right)_{\mathrm{n}}-\mathrm{N}^{+}\left(\mathrm{CH}_{3}\right) 3(\mathrm{~m}) ; \mathrm{n}=6,12 ; \mathrm{m}=8,10,14 \%$; Table 1).

(a)

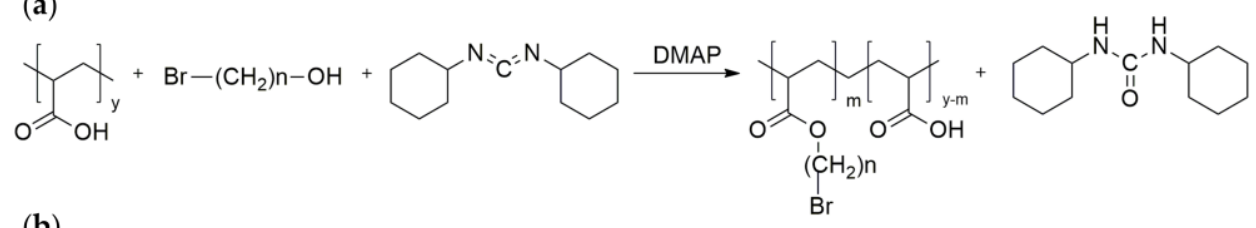

(b)

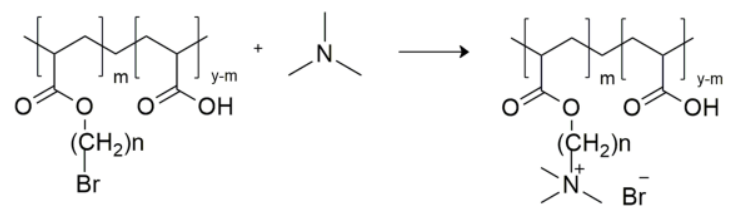

Scheme I. (a) Synthetic route of poly(acrylic acid) with bromine-terminated side alkyl chain (hexyl or dodecyl) obtained via Steglich esterification; (b) Synthesis of poly(acrylic acid) containing alkylene quaternary ammonium groupings by quaternisation with trimethylamine.

To avoid the undesirable reaction of trimethylamine with acid groups of poly(acrylic acid), the intermediate was neutralised after Steglich esterification with alcoholic sodium hydroxide solution. Direct quaternisation with a 10-fold excess of trimethylamine was performed at $4^{\circ} \mathrm{C}$ in a tightly closed vessel to avoid evaporation of volatile reagent. The above-mentioned synthesis allowed us to obtain the desired products under mild conditions, using simple purification methods (dialysis, freeze-drying). It should be emphasised that the recalled synthetic routes may constitute general repetitive methods of fabrication of numerous antimicrobial polyelectrolytes. 
Table 1. Structure and abbreviations of the alkylene quaternary ammonium salt decorated PAA derivatives.

\begin{tabular}{|c|c|c|c|c|}
\hline No & Structure & $\left(\mathrm{CH}_{2}\right)_{\mathrm{n}}$ & $\begin{array}{c}\% \text { degree of } \\
\text { substitution }(\mathrm{m})\end{array}$ & Abbreviation \\
\hline 1 & & & 8 & PAA-C(O)O- $\left(\mathrm{CH}_{2}\right)_{6}-\mathrm{N}^{+}\left(\mathrm{CH}_{3}\right)_{3}-8 \%$ \\
\hline 2 & & & 10 & PAA-C(O)O- $\left(\mathrm{CH}_{2}\right)_{6}-\mathrm{N}^{+}\left(\mathrm{CH}_{3}\right)_{3}-10 \%$ \\
\hline 3 & & & 8 & PAA-C(O)O- $\left(\mathrm{CH}_{2}\right)_{12}-\mathrm{N}^{+}\left(\mathrm{CH}_{3}\right)_{3}-8 \%$ \\
\hline 4 & & & 14 & PAA-C(O)O- $\left(\mathrm{CH}_{2}\right)_{12}-\mathrm{N}^{+}\left(\mathrm{CH}_{3}\right)_{3}-14 \%$ \\
\hline
\end{tabular}

The molecular structures of all antimicrobial functionalised PAA derivatives 1-4 were determined by ${ }^{1} \mathrm{H}$ NMR and FTIR techniques (Figure 1 and Figure 2, respectively). In the ${ }^{1} \mathrm{H}$ NMR spectra (for PAA modified with hexyl: PAA- $\mathrm{C}(\mathrm{O}) \mathrm{O}-\left(\mathrm{CH}_{2}\right)_{6}-\mathrm{N}^{+}\left(\mathrm{CH}_{3}\right)_{3}-8 \%$ and PAA-C $(\mathrm{O}) \mathrm{O}-\left(\mathrm{CH}_{2}\right)_{6}-\mathrm{N}^{+}\left(\mathrm{CH}_{3}\right)_{3}-10 \%$, or dodecyl: PAA-C $(\mathrm{O}) \mathrm{O}-\left(\mathrm{CH}_{2}\right)_{12}-\mathrm{N}^{+}\left(\mathrm{CH}_{3}\right)_{3}-8 \%$ and $\mathrm{PAA}-\mathrm{C}(\mathrm{O}) \mathrm{O}-\left(\mathrm{CH}_{2}\right)_{12}-\mathrm{N}^{+}\left(\mathrm{CH}_{3}\right)_{3}-14 \%$, alkyl chain ended with quaternary ammonium moiety; see Figure 1), a sharp signal is assigned to three methyl groups attached directly to the quaternary nitrogen atom (chemical shift $3.3 \mathrm{ppm}$ ). Moreover, a weaker signal (4.5 times by integration intensity, chemical shift $3.6 \mathrm{ppm}$ ) attributed to the methylene moiety directly bonded to the quaternary ammonium moiety was identified. Signals attributed to the repeating methylene and methine groups in the polyelectrolyte backbone, as well as repeating methylene moieties in the side chains, appeared as broad signals in the region of $1.1-2.4$ ppm [19]. It was impossible to assign the mentioned signals directly due to their overlap.

The values of the grafting ratio and degree of substitution (percentage of grafting) were estimated from ${ }^{1} \mathrm{H}$ NMR spectra, taking into account integrated signal intensities at $3.3 \mathrm{ppm}$ and in the range of $1.1-2.4 \mathrm{ppm}$, according to the protocol described by Wawrzynczyk et al. [21] The values of the grafting ratio (i.e. number of units (mers) in the PE backbone per unit grafted with the cationic group) were 11.8 (PAA-C $\left.(\mathrm{O}) \mathrm{O}-\left(\mathrm{CH}_{2}\right)_{6}-\mathrm{N}^{+}\left(\mathrm{CH}_{3}\right)_{3}-8 \%\right), \quad 9.7 \quad\left(\mathrm{PAA}-\mathrm{C}(\mathrm{O}) \mathrm{O}-\left(\mathrm{CH}_{2}\right)_{6}-\mathrm{N}^{+}\left(\mathrm{CH}_{3}\right)_{3}-10 \%\right), \quad 11.2$ $\left(\mathrm{PAA}-\mathrm{C}(\mathrm{O}) \mathrm{O}-\left(\mathrm{CH}_{2}\right)_{12}-\mathrm{N}^{+}\left(\mathrm{CH}_{3}\right)_{3}-8 \%\right.$ ) and 7.4 (PAA-C $\left.(\mathrm{O}) \mathrm{O}-\left(\mathrm{CH}_{2}\right)_{12}-\mathrm{N}^{+}\left(\mathrm{CH}_{3}\right)_{3}-14 \%\right)$. The corresponding grafting percentages were found to be $8 \%$ (PAA-C $\left.(\mathrm{O}) \mathrm{O}-\left(\mathrm{CH}_{2}\right)_{6}-\mathrm{N}^{+}\left(\mathrm{CH}_{3}\right)_{3}-8 \%\right), \quad 10 \% \quad\left(\mathrm{PAA}-\mathrm{C}(\mathrm{O}) \mathrm{O}-\left(\mathrm{CH}_{2}\right)_{6}-\mathrm{N}^{+}\left(\mathrm{CH}_{3}\right)_{3}-10 \%\right), \quad 8 \%$ (PAA-C $(\mathrm{O}) \mathrm{O}-\left(\mathrm{CH}_{2}\right)_{12}-\mathrm{N}^{+}\left(\mathrm{CH}_{3}\right)_{3}-8 \%$ ) and $14 \%\left(\mathrm{PAA}-\mathrm{C}(\mathrm{O}) \mathrm{O}-\left(\mathrm{CH}_{2}\right)_{12}-\mathrm{N}^{+}\left(\mathrm{CH}_{3}\right)_{3}-14 \%\right)$.

FTIR studies of synthesised A-QAS-PEs (products 1-4, Table 1) showed the presence of characteristic bands assigned to $\mathrm{O}-\mathrm{H}, \mathrm{C}-\mathrm{H}, \mathrm{C}=\mathrm{O}, \mathrm{C}-\mathrm{O}-\mathrm{C}$, and $\mathrm{C}-\mathrm{N}$ bonds that confirm their presence in functionalised polyelectrolytes. The presence of both carboxylate and ester groups was confirmed by signals (attributed to carbonyl stretching vibrations) at around 1643-1666 $\mathrm{cm}^{-1}$ and around 1702-1708 $\mathrm{cm}^{-1}$, respectively. The signals around 1465-1478 $\mathrm{cm}^{-1}$ correspond to $\mathrm{C}-\mathrm{N}$ bonds [39] in the quaternary ammonium moiety. However, they are partially overlapped with signals from alkyl C-H bonds $\left(\mathrm{CH}_{3}\right.$ and $\mathrm{CH}_{2}$ groups). 


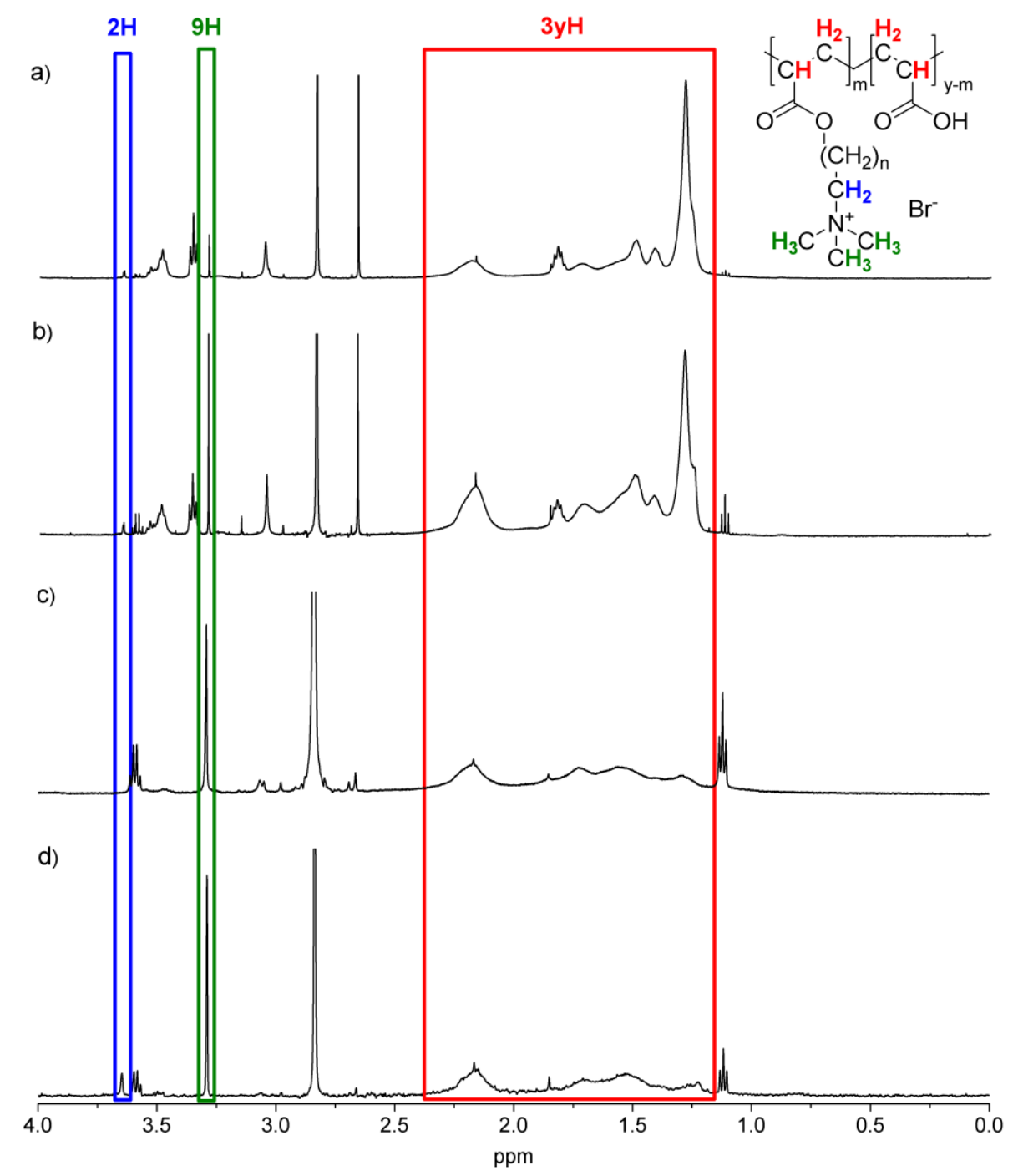

Figure 1. ${ }^{1} \mathrm{H}-\mathrm{NMR}$ spectra of PAA-C $(\mathrm{O}) \mathrm{O}-\left(\mathrm{CH}_{2}\right)_{12}-\mathrm{N}^{+}\left(\mathrm{CH}_{3}\right)_{3}-14 \%$ (a),

PAA-C(O)O- $\left(\mathrm{CH}_{2}\right)_{12}-\mathrm{N}^{+}\left(\mathrm{CH}_{3}\right)_{3}-8 \%$ (b), PAA-C(O)O- $\left(\mathrm{CH}_{2}\right)_{6}-\mathrm{N}^{+}\left(\mathrm{CH}_{3}\right)_{3}-10 \%$ (c) and

PAA-C $(\mathrm{O}) \mathrm{O}-\left(\mathrm{CH}_{2}\right)_{6}-\mathrm{N}^{+}\left(\mathrm{CH}_{3}\right)_{3}-8 \%$ (d) with marked signals attributed to the identified protons. 


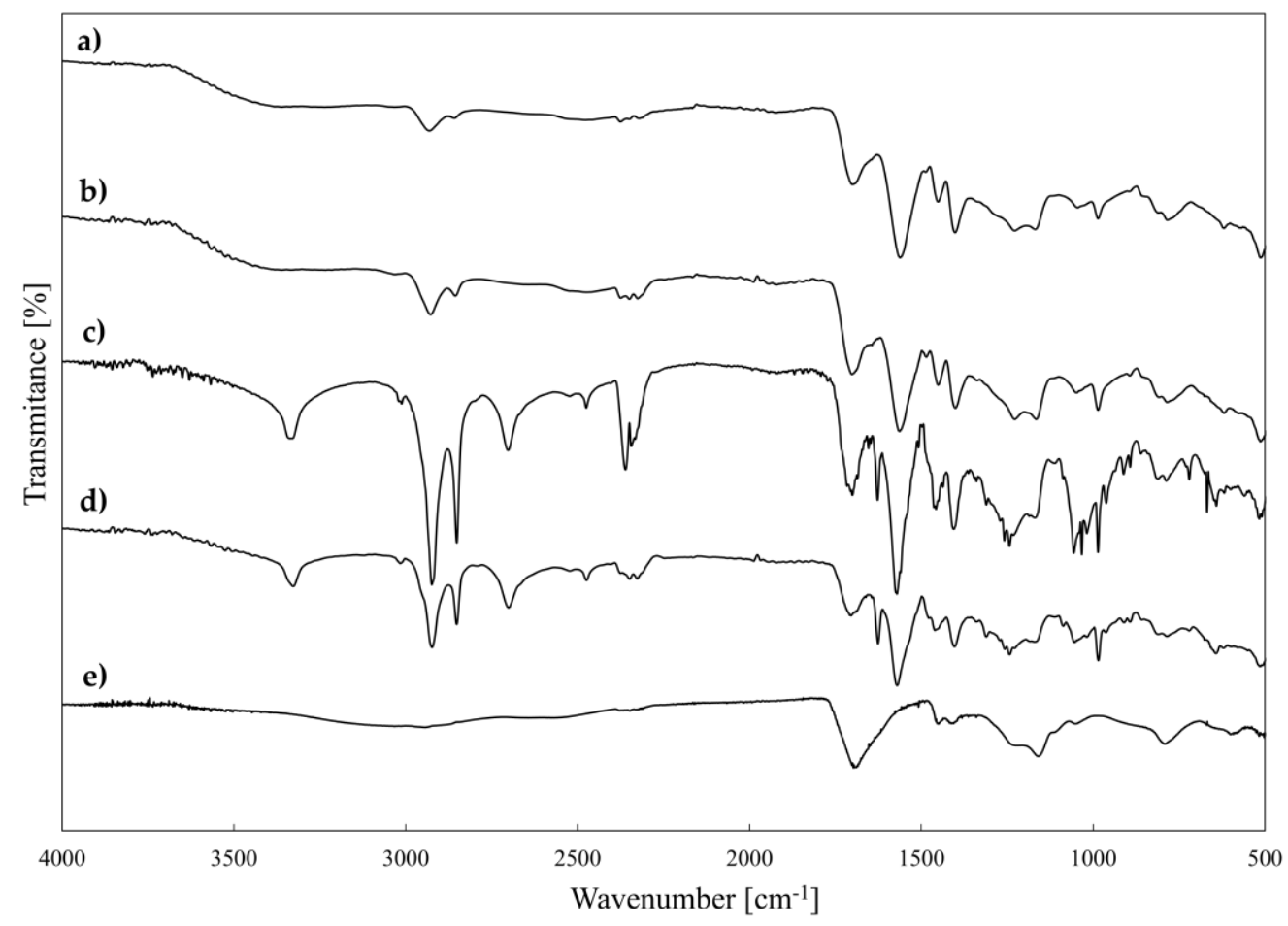

Figure 2. FTIR spectra of PAA- $\mathrm{C}(\mathrm{O}) \mathrm{O}-\left(\mathrm{CH}_{2}\right)_{6}-\mathrm{N}^{+}\left(\mathrm{CH}_{3}\right)_{3}-8 \%(\mathbf{a})$, $\mathrm{PAA}-\mathrm{C}(\mathrm{O}) \mathrm{O}-\left(\mathrm{CH}_{2}\right)_{6}-\mathrm{N}^{+}\left(\mathrm{CH}_{3}\right)_{3}-10 \%$ (b), PAA-C(O)O- $\left(\mathrm{CH}_{2}\right)_{12}-\mathrm{N}^{+}\left(\mathrm{CH}_{3}\right)_{3}-8 \%(\mathbf{c})$, PAA-C(O)O- $\left(\mathrm{CH}_{2}\right)_{12}-\mathrm{N}^{+}\left(\mathrm{CH}_{3}\right)_{3}-14 \%$ (d) and PAA (e).

\subsection{Characterisation of the obtained multifunctional microcarriers}

Strategies to construct properly designed microcarriers for multiple applications are guided by various factors: (i) appropriate physicochemical features: shape, size, stiffness, morphology, and surface charge; (ii) type of building blocks which should be of a biocompatible matter; (iii) appropriate chemical and colloidal stability; (iv) efficacious payload encapsulation; $(v)$ ease of surface functionalisation [25-27]. Taking these outlines into account, the synthetic route of microcapsules consisted of two major steps and, thus, integrated an emulsion method [25] to obtain alginate-based microspheres loaded with CUR and the LbL technique [26] to form bilayer microcapsules coated with CHIT or PAH and antimicrobial decorated polyelectrolytes 1-4 (for details, see Table 1: PAA-C(O)O- $\left.\left(\mathrm{CH}_{2}\right)_{\mathrm{n}}-\mathrm{N}^{+}\left(\mathrm{CH}_{3}\right)_{3}(\mathrm{~m}) ; \mathrm{n}=6,12 ; \mathrm{m}=8,10,14 \%\right)$ as schematically described in Figure 3. Two microcapsule systems were formed, differing in the number and type of coatings. Based on our previous research, the CHIT and PAH polymers were selected for the first coating layer for hydrogel microsystems [25, 40]. Then, hydrogels were coated with 1-4 polymers as the second layer. The concentrations of the core polymer and the payload used were the same in all types of microparticles fabricated. Variations in the composition, abbreviations, and characteristics of the fabricated bilayer microcarriers are presented in Table 2 . 


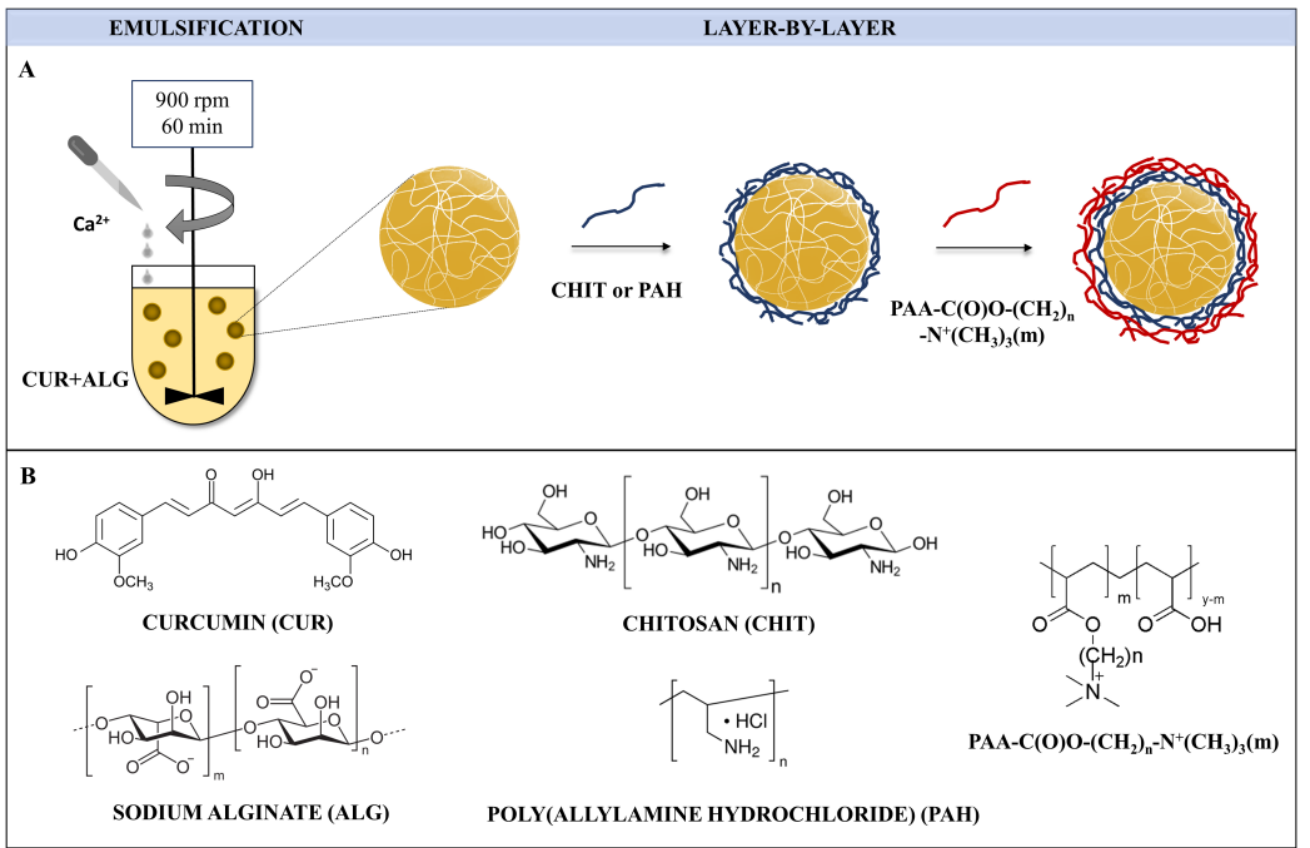

Figure 3. Fabrication process of bilayer CUR-loaded microparticles coated with alkylene quaternary ammonium salt grafted poly(acrylic acid) (denoted as PAA-C $(\mathrm{O}) \mathrm{O}-\left(\mathrm{CH}_{2}\right){ }_{n}-\mathrm{N}^{+}\left(\mathrm{CH}_{3}\right) 3(\mathrm{~m}) ; \mathrm{n}=6$, $12 ; \mathrm{m}=8,10,14 \%$; Table 1 ) as outer layer (A); Structures of microparticle components (B).

Table 2. Abbreviations, composition, and characteristics of the formulated CUR-loaded microparticles.

\begin{tabular}{|c|c|c|c|c|c|c|c|c|c|}
\hline \multicolumn{5}{|c|}{ CHIT system } & \multicolumn{5}{|c|}{ PAH system } \\
\hline $\begin{array}{c}\text { micro- } \\
\text { particles }\end{array}$ & $\begin{array}{c}\text { composition } \\
\text { of PE } \\
\text { coatings } \\
\end{array}$ & $\begin{array}{l}\mathrm{MD}^{\mathrm{a}} \\
{[\mu \mathrm{m}]}\end{array}$ & $\mathbf{P D I}^{\mathrm{b}}$ & $\begin{array}{l}E^{c} \\
{[\%]}\end{array}$ & $\begin{array}{c}\text { micro- } \\
\text { particles }\end{array}$ & $\begin{array}{c}\text { composition } \\
\text { of PE } \\
\text { coatings } \\
\end{array}$ & $\begin{array}{l}\mathrm{MD}^{\mathrm{a}} \\
{[\mu \mathrm{m}]}\end{array}$ & PDI ${ }^{b}$ & $\begin{array}{l}\mathrm{EE}^{\mathrm{c}} \\
{[\%]}\end{array}$ \\
\hline $\mathrm{CU}$ & uncoated & $45.9 \pm 4.9$ & 1.125 & $56.1 \pm 3.8$ & $\mathrm{CU}$ & uncoated & $45.9 \pm 4.9$ & 1.125 & $56.1 \pm 3.8$ \\
\hline $\mathrm{CC}$ & CHIT & $48.9 \pm 5.1$ & 1.143 & $58.5 \pm 4.8$ & $\mathrm{CP}$ & $\mathrm{PAH}$ & $60.7 \pm 6.1$ & 1.108 & $52.2 \pm 1.8$ \\
\hline $\mathrm{CCP}$ & CHIT/PAA & $47.3 \pm 5.9$ & 1.108 & $56.7 \pm 6.4$ & $\mathrm{CPP}$ & PAH/PAA & $59.0 \pm 5.4$ & 1.071 & $60.5 \pm 2.5$ \\
\hline CC1 & $\mathrm{CHIT} / 1^{*}$ & $46.2 \pm 4.8$ & 1.101 & $48.7 \pm 2.3$ & CP1 & $\mathrm{PAH} / 1^{*}$ & $57.2 \pm 4.0$ & 1.044 & $53.8 \pm 3.2$ \\
\hline $\mathrm{CC} 2$ & $\mathrm{CHIT} / 2^{*}$ & $50.9 \pm 6.0$ & 1.121 & $53.9 \pm 2.9$ & $\mathrm{CP2}$ & $\mathrm{PAH} / 2^{*}$ & $56.9 \pm 6.3$ & 1.083 & $45.8 \pm 1.9$ \\
\hline CC3 & $\mathrm{CHIT} / 3^{*}$ & $50.0 \pm 4.4$ & 1.120 & $48.3 \pm 3.0$ & CP3 & $\mathrm{PAH} / 3^{*}$ & $59.5 \pm 5.7$ & 1.069 & $44.6 \pm 1.1$ \\
\hline CC4 & $\mathrm{CHIT} / 4^{*}$ & $48.1 \pm 5.1$ & 1.111 & $55.4 \pm 1.7$ & $\mathrm{CP} 4$ & $\mathrm{PAH} / 4^{*}$ & $58.9 \pm 6.2$ & 1.077 & $56.2 \pm 2.7$ \\
\hline
\end{tabular}

a MD-mean diameter

b PDI-polydispersity index

c EE-encapsulation efficiency

* 1-4: alkylene quaternary ammonium salt functionalised poly(acrylic acid) (for details see Table 1).

The results are expressed as mean \pm S.D.

Investigations of the surface morphology and shape of the dried microparticles were carried out by SEM, and representative micrographs are shown in Figure 4. Most of the microparticles were of similar spherical shape, and the polyelectrolyte coatings did not cause any significant changes in the shape of the microcapsules. However, there were differences in surface morphology. SEM images have shown that the surface of microparticles functionalised with antimicrobial decorated PAA slightly differs depending on the type of polyelectrolyte 1-4 (see Table 1) used as the outer layer. In the case of the CHIT system microcarriers, the CC3 and CC4 surfaces were more porous and wrinkled than the $\mathrm{CC} 1$ and $\mathrm{CC} 2$ ones, probably due to evaporation of a larger amount of water trapped within the outer layer of the microparticles. The external surfaces of microcapsules with PAH turned out to be similar to each other. Moreover, the CUs had a smoother surface than the other microcarriers. Comparing all coated microparticles, it is clearly 
visible that the CPs had a less rugged and irregular surface than other microcapsules. Thus, the PE shell appears to be the factor that affects the surface morphology [27].

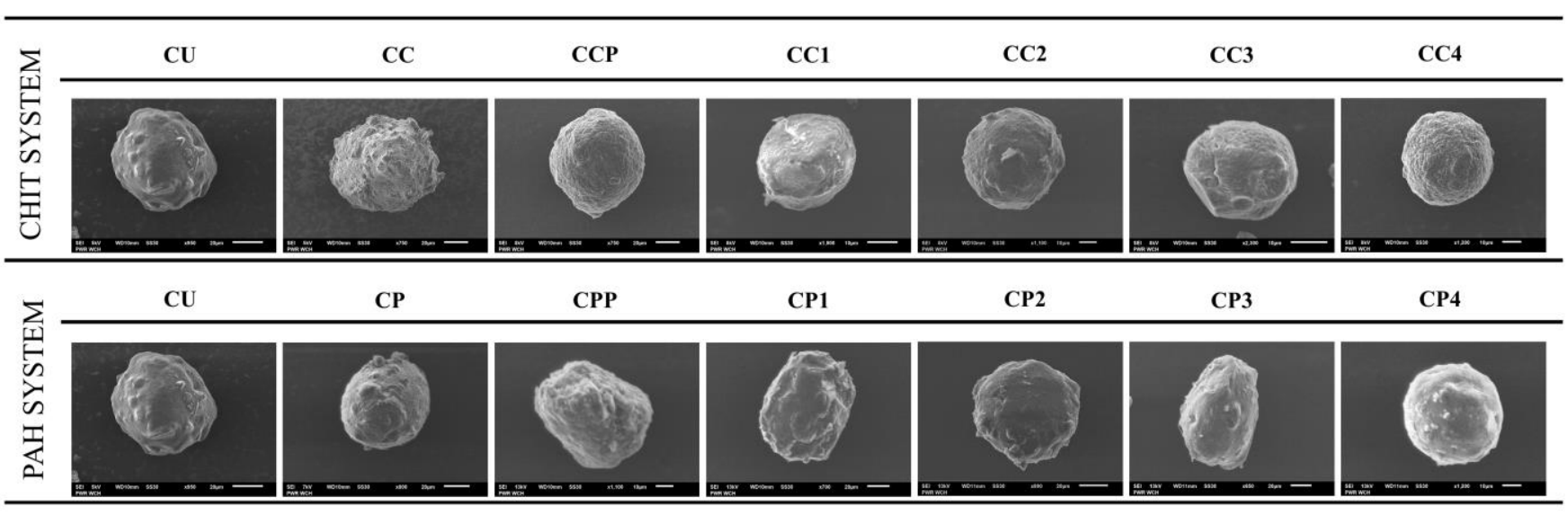

Figure 4. SEM images of CUR-loaded microparticles of CHIT and PAH systems (for details, see Table 2).

The mean diameter values (MD) of all fabricated bilayer microparticles are shown in Table 2. Examination of the microcarriers size revealed some differences in MD between microspheres and coated microcapsules. The uncoated microparticles were characterised by a lower MD $(45.9 \pm 4.9 \mu \mathrm{m})$ than coated ones. Furthermore, the MD of PAH-coated microcapsules (CP, CPP, CP1, CP2, CP3, and CP4) was higher than the MD of the CHIT-coated microcapsules (CC, CCP, CC1, CC2, CC3, and CC4), possibly due to the acidic conditions during the deposition of the chitosan layer. That resulted in the reduced repulsive interactions of alginate carboxyl groups and shrinkage of the alginate core. Further coating of the microparticles with either PAA or 1-4 alkylene quaternary ammonium salt functionalised poly(acrylic acid) did not change their size; however, the PDI values for all the fabricated microparticles indicate their high polydispersity. Our results suggest that the type of the first PE coating and the conditions of its deposition had the most significant effect on the size of the microcapsules [41].

Encapsulation efficiency (EE) represents a crucial parameter that affects the quality of microparticles. The EE values for the developed microparticles are reported in Table 2. They revealed only slight differences between the values for uncoated microspheres and microcapsules coated with the modified polyelectrolytes 1-4. For the CHIT containing microcapsules, the decrease of the EE in most cases is within the experimental error. A stronger decrease of the EE could be observed for PAH containing capsules, in particular for CP2 and CP3. That can result from the higher porosity of the outer coating with the more hydrophobic polyelectrolyte. However, the EE of all fabricated microparticles was satisfactory for CUR encapsulation in microparticles [42].

Curcumin-loaded microcarriers coated with the grafted polyelectrolytes 1-4 (i.e., alkylene quaternary ammonium salt modified poly(acrylic acid)) were studied by FTIR and the most characteristic bands reflecting structural features were identified in the spectra shown in Figure S1. The spectra of other types of microparticles and curcumin were presented in the electronic supplementary material (Figure S2). FTIR analysis confirmed that CUR was successfully encapsulated in the alginate-based microparticles and CHIT or PAH, and antimicrobial decorated PAAs were adsorbed onto the core. The characteristic peaks of CUR are present in spectra of all types of microparticles. The signals at $3500 \mathrm{~cm}^{-1}$ correspond to the hydroxyl groups, and the peaks in the region between 1629-1635 $\mathrm{cm}^{-1}$ are associated with carbonyl $(-\mathrm{C}=\mathrm{O})$ groups of CUR [43]. The bands from 1575 to $1608 \mathrm{~cm}^{-1}$ are attributed to the $\mathrm{C}=\mathrm{C}$ stretching vibrations of aromatic rings, and the bands located at 1130-1160 $\mathrm{cm}^{-1}$ are from ether (C-O-C) groups in the structure of CUR. The peaks at around $1500 \mathrm{~cm}^{-1}$ are attributed to stretching vibrations of C-C bands present in the aromatic ring, and signals observed in the region between $700-900 \mathrm{~cm}^{-1}$ are assigned to C-H bands of CUR [44]. Furthermore, FTIR spectra of microparticles re- 
vealed the presence of characteristic signals for sodium alginate: wide bands in the range of 3070-3450 $\mathrm{cm}^{-1}$ are from hydroxyl $(\mathrm{O}-\mathrm{H})$ groups [45], the peaks at $1628 \mathrm{~cm}^{-1}$ are related to the asymmetric stretching vibration of carboxylate groups $(-\mathrm{COOH})$, the signals at $1603 \mathrm{~cm}^{-1}$ correspond to the symmetric vibrations of carboxylate groups [46] and the signals around 1050-1110 $\mathrm{cm}^{-1}$ originate from C-O-C glycosidic bonds. Furthermore, FTIR measurements confirmed the presence of polyelectrolytes applied as microparticle coatings. The $-\mathrm{NH}_{2}$ group of CHIT and $\mathrm{PAH}$ provided the peak corresponding to the bending vibrations of $\mathrm{N}-\mathrm{H}$ at $1540-1550 \mathrm{~cm}^{-1}$ [47]. The signals form C-N stretching vibrations, present in the structure of CHIT and the series of PAA-C(O)O- $\left(\mathrm{CH}_{2}\right)_{\mathrm{n}}-\mathrm{N}^{+}\left(\mathrm{CH}_{3}\right)_{3}(\mathrm{~m})$ $\left(\mathrm{n}=6,12 ; \mathrm{m}=8,10,14 \%\right.$; products no. 1-4 in Table 1) were visible at $1460 \mathrm{~cm}^{-1}-1490 \mathrm{~cm}^{-1}$ [39] while the C-N stretching vibrations from the PAH structure were observed in the region from $1340 \mathrm{~cm}^{-1}$ to $1350 \mathrm{~cm}^{-1}$. The peaks in the range of $2842-2956 \mathrm{~cm}^{-1}$ resulted from the $\mathrm{C}-\mathrm{H}$ stretching vibrations in alkyl chains of A-QAS-PEs. Furthermore, bands in $1660-1680 \mathrm{~cm}-1$ related to the $\mathrm{C}=\mathrm{O}$ bond in the amide groups confirm the formation of electrostatic complexes between the carboxylic group of ALG, PAA A-QAS-PEs, and the amino group of CHIT or PAH [40].

\subsection{Features of the LbL coatings studied by QCM-D, ellipsometry, and zeta potential measure- ments}

Understanding the mechanism of polyelectrolyte deposition and the determination of film parameters, including thickness, mass, viscosity, and zeta potential, is fundamental for building multilayer films. The assembly of polyelectrolyte multilayer films on solid substrates was monitored in real time by QCM-D measurements to study adsorption kinetics and viscoelastic properties of the PE layers. Our experiments were performed in a particular manner to reproduce the sequence of the microparticles fabrication process: after PEI was used as an anchor layer at gold-coated QCM crystals, a crosslinked ALG layer loaded with CUR was deposited and crosslinked with $\mathrm{CaCl}_{2}$ to mimic the core of microparticles, then CHIT or PAH was adsorbed as the first coating layer, and 1-4 functionalised polyelectrolytes (see Table 1) as the outer layer. Figure 5 and Figure S3 display the buildup of the multilayer film analysed in terms of normalised frequency changes $(\Delta \mathrm{f})$ and energy dissipation shifts $(\Delta \mathrm{D})$ upon the adsorption of PEs. The typical decrease in the oscillation frequency observed during the deposition cycle indicates the increased mass on the sensor surface. The energy dissipation is related to the viscoelastic properties of the PE film: if the measured dissipation value is above $1 \times 10^{-6}$ per $10 \mathrm{~Hz}$ frequency shift and spreads for overtones, the adsorbed layer is soft; if the dissipation value is less than $1 \times 10^{-6}$ per $10 \mathrm{~Hz}$ frequency shift the deposited film is rigid [34].

When the surface of the quartz crystal was rinsed with distilled water, the frequency increased slightly due to the desorption of weakly bound polyelectrolyte molecules. Conversely, energy dissipation increased with adsorption of subsequent PE layer and decreased during the rinsing step. Overall, the results showed in Figure 5 and Figure S3 confirmed the successful assembly of each polyelectrolyte on gold-coated quartz sensors. 

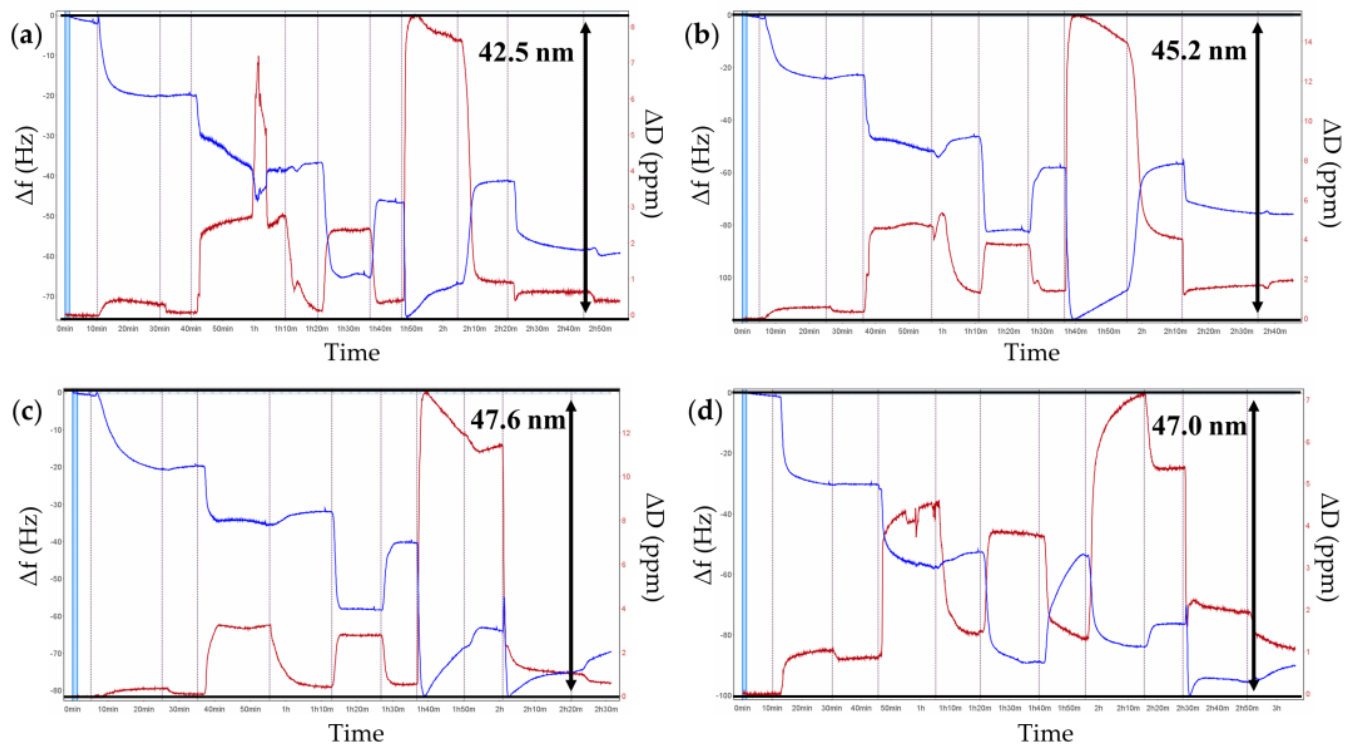

Figure 5. Exemplary graphs of adsorption kinetic measurements of polyelectrolyte multilayers monitored by QCM-D: (a) PEI/CUR/ALG/CHIT/1; (b) PEI/CUR/ALG/CHIT/2;

(c) PEI/CUR/ALG/CHIT/3;(d) PEI/CUR/ALG/CHIT/4. Blue lines illustrate frequency shifts $(\Delta \mathrm{f})$, red lines illustrate dissipation shifts $(\Delta \mathrm{D})$ of polyelectrolyte multilayers. Resonance frequency variations and dissipation variations are recorded as a function of time. Normalised frequency and dissipation shifts are shown for the seventh overtone.

Analysis of the QCM-D results indicated that $\mathrm{Ca}^{2+}$ crosslinked CUR-ALG layer formed rather stiff films as the energy dissipation was relatively low $\left(4 \times 10^{-6}\right)$. Deposition of the polycation layer CHIT or PAH led to the mass increase of the film and energy dissipation, presumably due to hydration. Consecutive adsorption of PAA or the 1-4 polyelectrolytes caused a further decrease of the frequency (adsorption) and stiffening of the film, which can be attributed to the collapse of the entire multilayer structure toward the interface during the adsorption of PAA and PAA-C $(\mathrm{O}) \mathrm{O}-\left(\mathrm{CH}_{2}\right)_{n}-\mathrm{N}^{+}\left(\mathrm{CH}_{3}\right)_{3}(\mathrm{~m})$ with the consequent formation of a rigid and thin structure [48].

The QCM-D technique enabled us to quantitatively analyse the mass, thickness, and viscosity of adsorbed films applying the viscoelastic film model (see section 3.9), as presented in Table 3. PAH forms a thicker and denser layer than CHIT, in agreement with the data reported in Table 2. In addition, for the CHIT system, the thickness of each bilayer system (CHIT/A-QAS-PEs) is lower than in the case of the bilayer PAH system (PAH/A-QAS-PEs). The thickness/mass of the outer layer was the lowest for the unmodified PAA and the highest for the functionalised polyelectrolytes with $-\left(\mathrm{CH}_{2}\right)_{12}$ - hydrocarbon chain irrespective of the polycation layer. These differences can be related to the higher molecular mass of those polyelectrolytes. The results of the viscosity for both systems revealed the opposite trend than for thickness or areal mass - the viscosity of the outer layers (PAA or PAA-C $(\mathrm{O}) \mathrm{O}-\left(\mathrm{CH}_{2}\right)_{\mathrm{n}}-\mathrm{N}^{+}\left(\mathrm{CH}_{3}\right)_{3}(\mathrm{~m})$ ) was higher than the viscosity of the polycation layers (CHIT or PAH). That means that the multilayer structure is more rigid with the PAA used as the final layer, as indicated by energy dissipation results.

The spectroscopic ellipsometry allowed measuring the thickness of dry film layers, and the obtained results are listed in the Electronic Supplementary Material (Table S1). The ratio of the dry thickness of the CHIT layer $(1.4 \mathrm{~nm})$ and PAH layer $(2.2 \mathrm{~nm})$ agreed with the QCM-D results for wet thickness as the CHIT layer was thinner than the PAH one. The dry thickness of PAA-C $(\mathrm{O}) \mathrm{O}-\left(\mathrm{CH}_{2}\right)_{6}-\mathrm{N}^{+}\left(\mathrm{CH}_{3}\right)_{3}-8 \%$ and PAA-C $(\mathrm{O}) \mathrm{O}-\left(\mathrm{CH}_{2}\right)_{6}-\mathrm{N}^{+}\left(\mathrm{CH}_{3}\right)_{3}-10 \%$ was much higher than PAA-C $(\mathrm{O}) \mathrm{O}-\left(\mathrm{CH}_{2}\right)_{12}-\mathrm{N}^{+}\left(\mathrm{CH}_{3}\right)_{3}-8 \%$ and PAA- $(\mathrm{O}) \mathrm{O}-\left(\mathrm{CH}_{2}\right)_{12}-\mathrm{N}^{+}\left(\mathrm{CH}_{3}\right)_{3}-14 \%$ regardless of the polycation layer underneath, unlike the thickness of the respective wet film layers. It 
can be the effect of weaker hydration in the dry state of modified polyelectrolytes containing more hydrophobic side chains.

Since the formation of the multilayer coatings is mainly driven by the electrostatic interactions, we determined the zeta potentials of the polyelectrolyte building blocks of the films. The results are presented in Table 3. As expected, the values for cationic PEs exhibited a positive charge: $\zeta_{\mathrm{CHIT}}=40.9 \mathrm{mV}, \zeta_{\mathrm{PAH}}=35.7 \mathrm{mV}$. The zeta potential for unmodified PAA was $\zeta=-17.3 \mathrm{mV}$, whereas for $\mathbf{1 - 4}$ polyelectrolytes was, respectively, in the range of -35.8 to $-26.7 \mathrm{mV}$, despite their functionalisation with positively charged quaternary amine groups. That difference can result from the lower $\mathrm{pH}$ of the PAA solution and the respective protonation of carboxylic groups. Similar absolute values of oppositely charged zeta potential enabled a successful sequential deposition of the PEs on both the solid substrates and the formation of the bilayer on hydrogel microparticles [49].

Table 3. Characteristics of the PE layers analysed with the QCM-D measurements.

\begin{tabular}{|c|c|c|c|c|c|}
\hline & PE layer & $\begin{array}{c}\text { thickness } \\
\text { [nm] }\end{array}$ & $\begin{array}{c}\text { areal mass } \\
{\left[\mu \mathrm{g} / \mathrm{cm}^{2}\right]}\end{array}$ & $\begin{array}{c}\text { viscosity } \\
{\left[\mathrm{g} / \mathrm{ms}^{2}\right]}\end{array}$ & $\begin{array}{c}\text { zeta potential } \\
{[\mathrm{mV}]}\end{array}$ \\
\hline \multirow{6}{*}{ 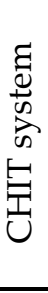 } & CHIT & $17.9 \pm 2.2$ & $1.9 \pm 0.2$ & $2.5 \pm 0.4$ & $41 \pm 5$ \\
\hline & PAA & $9.6 \pm 3.0$ & $1.0 \pm 0.3$ & $6.1 \pm 0.9$ & $-17.3 \pm 1.0$ \\
\hline & PAA-C $(\mathrm{O}) \mathrm{O}-\left(\mathrm{CH}_{2}\right)_{6}-\mathrm{N}^{+}\left(\mathrm{CH}_{3}\right)_{3}-8 \%$ & $10.6 \pm 0.1$ & $1.1 \pm 0.1$ & $7.9 \pm 1.8$ & $-31 \pm 5$ \\
\hline & PAA-C $(\mathrm{O}) \mathrm{O}-\left(\mathrm{CH}_{2}\right)_{6}-\mathrm{N}^{+}\left(\mathrm{CH}_{3}\right)_{3}-10 \%$ & $13.3 \pm 0.5$ & $1.3 \pm 0.1$ & $4.9 \pm 2.1$ & $-27 \pm 1.1$ \\
\hline & PAA-C $(\mathrm{O}) \mathrm{O}-\left(\mathrm{CH}_{2}\right)_{12}-\mathrm{N}^{+}\left(\mathrm{CH}_{3}\right)_{3}-8 \%$ & $15.7 \pm 3.9$ & $1.7 \pm 0.4$ & $7.3 \pm 1.0$ & $-32.5 \pm 2.0$ \\
\hline & PAA-C $(\mathrm{O}) \mathrm{O}-\left(\mathrm{CH}_{2}\right)_{12}-\mathrm{N}^{+}\left(\mathrm{CH}_{3}\right)_{3}-14 \%$ & $15.1 \pm 1.7$ & $1.6 \pm 0.2$ & $7.1 \pm 2.7$ & $-36 \pm 2.5$ \\
\hline \multirow{6}{*}{ 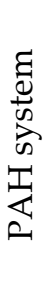 } & PAH & $22.8 \pm 3.4$ & $2.8 \pm 0.6$ & $2.1 \pm 0.5$ & $36 \pm 2.8$ \\
\hline & PAA & $13.2 \pm 2.5$ & $1.3 \pm 0.7$ & $3.4 \pm 0.4$ & $-17.3 \pm 1.0$ \\
\hline & PAA-C $(\mathrm{O}) \mathrm{O}-\left(\mathrm{CH}_{2}\right)_{6}-\mathrm{N}^{+}\left(\mathrm{CH}_{3}\right)_{3}-8 \%$ & $14.7 \pm 1.3$ & $1.5 \pm 0.2$ & $4.9 \pm 0.6$ & $-31 \pm 5$ \\
\hline & PAA-C $(\mathrm{O}) \mathrm{O}-\left(\mathrm{CH}_{2}\right)_{6}-\mathrm{N}^{+}\left(\mathrm{CH}_{3}\right)_{3}-10 \%$ & $16.7 \pm 1.7$ & $1.8 \pm 0.3$ & $5.4 \pm 1.6$ & $-26.7 \pm 1.1$ \\
\hline & PAA-C $(\mathrm{O}) \mathrm{O}-\left(\mathrm{CH}_{2}\right)_{12}-\mathrm{N}^{+}\left(\mathrm{CH}_{3}\right)_{3}-8 \%$ & $20.5 \pm 3.5$ & $2.1 \pm 0.4$ & $3.2 \pm 0.6$ & $-33 \pm 1.7$ \\
\hline & PAA-C $(\mathrm{O}) \mathrm{O}-\left(\mathrm{CH}_{2}\right)_{12}-\mathrm{N}^{+}\left(\mathrm{CH}_{3}\right)_{3}-14 \%$ & $18.9 \pm 4.0$ & $1.9 \pm 0.6$ & $3.1 \pm 0.9$ & $-36 \pm 2.4$ \\
\hline
\end{tabular}

\subsection{Curcumin release behavior}

The payload release mechanism under the required conditions plays a fundamental role in determining the ability of microcarriers to administer the active compound. The release profile of the enclosed substance depends on several factors, such as the payload and formulation characteristics and the fabrication process parameters. To determine the applicability of the designed microparticles as the curcumin carriers, their release behaviour was evaluated in a PBS solution at $\mathrm{pH}$ 7.4. The CUR release profiles of the microcarriers coated with the alkylene quaternary ammonium salt modified PAAs 1-4 (see Table 1) are presented in Figure 6 and Figure 7, while the CUR release profiles of the other types of microcarriers are presented in the Electronic Supplementary Material (Figure S4). CUR was released from the CHIT system microparticles faster than from those of the PAH system, which behaviour can be associated with the outer shell thickness because the CHIT system bilayers are thinner than those of the PAH system. Comparing the CUR release of all functionalised microcarriers, the highest release rate was observed for CC3 and CC4, which showed the initial burst release $(42 \%$ and $45 \%$ of the payload, respectively), while such an effect was not observed for CC1 and CC2. In the case of the PAH system microparticles, the slowest release rate of CUR was noticed for $\mathrm{CP} 1$ and $\mathrm{CP} 2$. The CP3 and CP4 showed a higher release rate with a significant burst effect $(22 \%$ and $15 \%$ of the payload, respectively).

Based on these findings, we can conclude that 3 and 4 polyelectrolytes form thicker, more hydrophobic layers with higher compatibility with curcumin than the microcapsules interior; therefore, CUR can accumulate there during microcapsules formation and is fastly released. On the other hand, polyelectrolytes $\mathbf{1}$ and $\mathbf{2}$ applied as the outer layer 
(on CHIT or PAH) form more compact and close-packed structures, which impede the payload release rate (cf. Fig 4). The CUR release profiles of CU and CC were similar, with initial burst release, but the faster CUR release kinetics was observed from the CC particles. The CP microcarriers demonstrated a slower release rate with no burst effect.

We attempted to describe the CUR release kinetics from the microcapsules quantitatively by the phenomenologic model. We selected the hybrid model $(\mathrm{H})$ that was previously found to be the most suitable for characterising the release of CUR. It combines first-order kinetics (FO) to describe the burst phase and the Korsmeyer-Peppas (KP) model to describe the further stage of the release [41]. The fitting of the $\mathrm{H}$ model to the experimental data resulted in a good fit with a high $\mathrm{R}^{2}$ value $(>0.953)$ (c.f., Figures 6, 7 and S3) for all compositions of the microparticles. In addition, the primary release mechanism after the burst phase could be determined for all microparticle types because the KP model can be used to study payload release from spherical, swellable hydrogel particles. The description of the release mechanism requires the examination of the release exponent coefficient $(n)$ : if $n \leqslant 0.43$, the release depends on Fickian diffusion, if $0.43<n<0.85$, the payload release is the result of diffusion and relaxation of the polymer chains, if $n>0.85$ the release is controlled by the supercase II transport [50].

The results for the best-fit parameters of the $\mathrm{H}$ model for the CUR release profiles from all types of microparticles are collected in Table 4 . The $n$ value for uncoated and CHIT- or PAH-coated microparticles suggests diffusion was the primary CUR release mechanism. The single PAA layer as the microparticles coating did not modify the release mechanism. Similarly, for all chitosan-based bilayer systems, the CUR diffusion out of the microparticles governs the release kinetics. On the other hand, the release of CUR from PAH/PE bilayer microparticles can also be associated with the relaxation of the polymer, as $\mathrm{n}>0.43$ was observed. These findings are in line with the QCM-D results showing that the 1-4 layers adsorbed on PAH form thicker layers (relatively to CHIT) that can relax during the release. In particular, for CP1 and CP2, the $n$ values are higher than those for CP3 and CP4, suggesting that the side chains interaction of polyelectrolytes 1 and $\mathbf{2}$ with PAH "seals" the outer shell of the particles. Therefore, the CUR release requires the microparticles surface reorganisation (i.e. loosening of the polymer chains). Probably, the $\mathbf{3}$ and $\mathbf{4}$ grafted PAAs, deposited on PAH may form more porous shells with hydrophobic domains more favourable for the diffusion of CUR. Therefore, switching the payload release mechanism from diffusion to diffusion/relaxation of the polymer can be controlled by the thickness and stiffness of the PE bilayer films (Figure 5 and Table 3). 

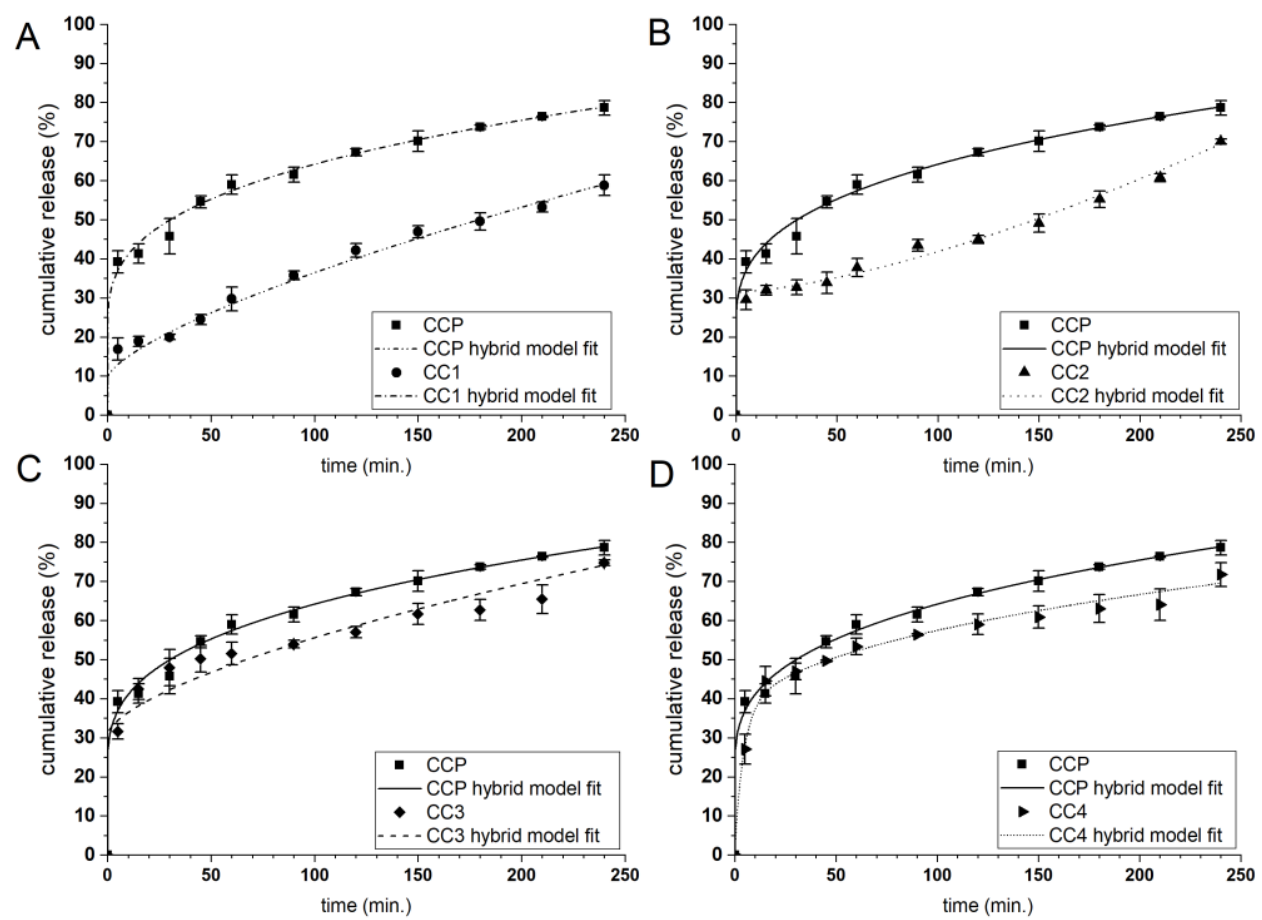

Figure 6. The curcumin release profiles in PBS solution $(\mathrm{pH}=7.4)$ from CHIT coated microparticles with the antimicrobial decorated poly(acrylic acid): 1 (A); 2 (B); 3 (C) and 4 (D). The lines correspond to the fitting curves of the hybrid model to the payload release profiles.
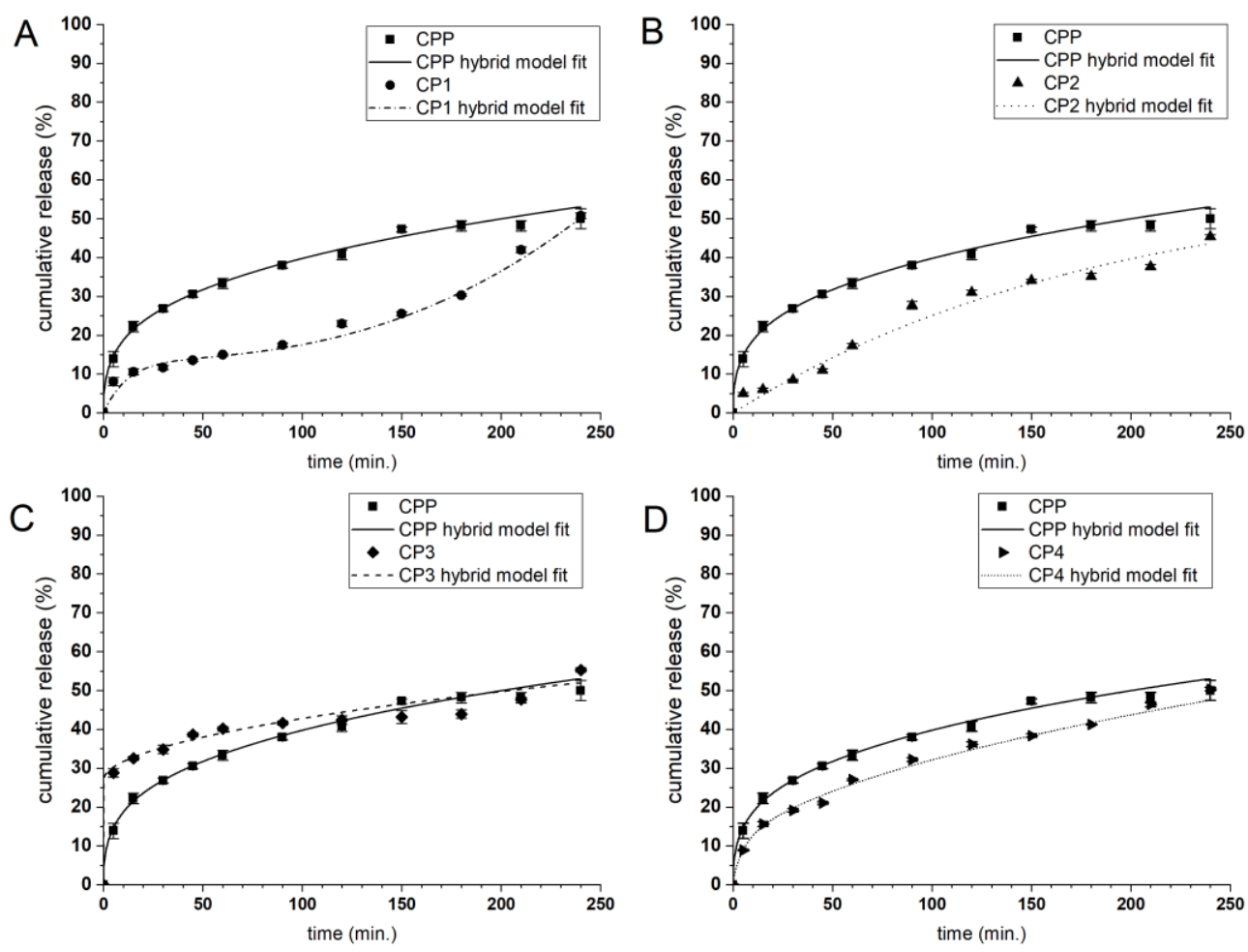

Figure 7. CUR release profiles in PBS solution $(\mathrm{pH}=7.4)$ from microparticles of PAH system coated with the antimicrobial decorated poly(acrylic acid): 1 (A); 2 (B); 3 (C) and 4 (D). The lines correspond to the fitting curves of the hybrid model to the payload release profiles. 
Table 4. The kinetic parameters of the hybrid model obtained from the fit to the experimental release profiles of CUR from the microparticles of CHIT and PAH systems.

\begin{tabular}{|c|c|c|c|c|c|c|}
\hline \multicolumn{2}{|c|}{ microparticles } & $\mathbf{M}$ & $\mathbf{k}_{1}$ & $\mathbf{k}_{2}$ & $\mathbf{n}$ & $\mathbf{R}^{2}$ \\
\hline \multirow{7}{*}{ 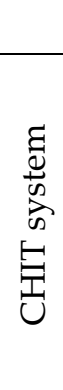 } & $\mathrm{CU}$ & 0.005 & $1.00 \mathrm{E}-03$ & $3.2 \mathrm{E}-01$ & 0.18 & 0.977 \\
\hline & $\mathrm{CC}$ & 0.005 & $1.00 \mathrm{E}-03$ & $3.9 \mathrm{E}-01$ & 0.16 & 0.980 \\
\hline & $\mathrm{CCP}$ & 0.005 & $1.00 \mathrm{E}-03$ & 2.3E-01 & 0.22 & 0.992 \\
\hline & $\mathrm{CC} 1$ & 1.420 & $1.00 \mathrm{E}-03$ & 9.3E-02 & 0.20 & 0.995 \\
\hline & $\mathrm{CC} 2$ & 1.127 & $1.00 \mathrm{E}-03$ & $1.8 \mathrm{E}-01$ & 0.15 & 0.973 \\
\hline & CC3 & 0.005 & $1.00 \mathrm{E}-03$ & 2.3E-01 & 0.20 & 0.985 \\
\hline & CC4 & 0.005 & $1.00 \mathrm{E}-03$ & 2.2E-01 & 0.21 & 0.985 \\
\hline \multirow{6}{*}{ 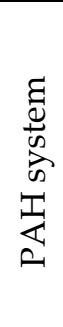 } & $\mathrm{CP}$ & 1.000 & $1.94 \mathrm{E}-03$ & $1.4 \mathrm{E}-01$ & 0.18 & 0.985 \\
\hline & СРP & 0.005 & $1.00 \mathrm{E}-03$ & $9.2 \mathrm{E}-02$ & 0.31 & 0.997 \\
\hline & $\mathrm{CP} 1$ & 0.005 & $1.00 \mathrm{E}-03$ & $5.8 \mathrm{E}-03$ & 0.79 & 0.953 \\
\hline & $\mathrm{CP} 2$ & 0.005 & $1.00 \mathrm{E}-03$ & $1.1 \mathrm{E}-02$ & 0.67 & 0.987 \\
\hline & $\mathrm{CP} 3$ & 0.005 & $1.00 \mathrm{E}-03$ & $1.9 \mathrm{E}-01$ & 0.47 & 0.969 \\
\hline & $\mathrm{CP} 4$ & 0.005 & $1.00 \mathrm{E}-03$ & $4.2 \mathrm{E}-02$ & 0.45 & 0.997 \\
\hline
\end{tabular}

2.5. Antimicrobial activity of bilayer CUR-loaded hydrogel microcarriers with antimicrobial decorated poly(acrylic acid) as the outer layer

Multilayer microcarriers covered by A-QAS-PEs, which comprise cationic moieties in the outer layer structure, possess antimicrobial properties due to a general mechanism driven by electrostatic interactions between the cationic surface of the carrier and the negatively charged sites of the bacteria membrane. Such a mechanism can be influenced by the following parameters: (i) the composition of the antimicrobial microparticles; (ii) the nature of polyelectrolytes with antimicrobial function; (iii) the cell membrane composition; (iv) the environmental parameters (i.e. temperature). In the present work, the antibacterial activity against $S$. aureus and $S$. marcescens of both antimicrobial decorated PAAs (1-4) and CUR-loaded hydrogel microparticles with 1-4 PAAs as the outer layer was determined using the disc diffusion method. The results expressed as an inhibition zone diameter $(\Phi)$ are given in Table 5 and illustrated in Figure 8.

We observed a small inhibition zone for unmodified PAA, but the PAA antimicrobial grafting increased the inhibitory activity against both strains of bacteria. Even though synthesised polyelectrolytes 1-4 used as the outer layer in the bilayer microparticles had the negative zeta potential, the presence of quaternary ammonium groups responsible for microbial cell damage significantly enhanced their antibacterial action. It is worthy to note that higher antimicrobial activity was observed against $S$. aureus $(\Phi=10$ $12 \mathrm{~mm}$ ) than against $S$. marcescens $(\Phi=7 \mathrm{~mm})$ for all studied bilayer hydrogel microcarriers with antimicrobial decorated PAA as the outer layer. It seems that Gram-positive bacteria could be more sensitive to the A-QAS-PEs representatives. That behaviour may be related to the structure of the bacterial cell envelope. The Gram-positive bacteria consists of an inner membrane and a cell wall compared to the presence of an additional outer membrane in the cell envelope of Gram-negative bacteria [1, 51]. Moreover, the hydrophobicity and the degree of substitution of cationic moieties influenced the antimicrobial activity of the new PEs. Moreover, the functionalised polyelectrolyte $\mathbf{1}$ and $\mathbf{2}$ showed higher antibacterial efficacy against the strain of Gram-positive bacteria than 3 and 4 . That can be explained by the longer side alkyl chains in the structures of $\mathbf{3}$ and $\mathbf{4}$, which form a hydrophobic barrier between positively charged units and the surface of the bacterial cell. Moreover, the shorter alkyl chains of $\mathbf{1}$ and $\mathbf{2}$ are more mobile in the microbial culture medium, and their cationic moieties can interact more effectively with the bacterial wall [12]. The higher grafting degree improved the inhibition effect against Gram-positive bacteria, as the $\Phi$ was higher for decorated polyelectrolyte 4. 
Our study indicated that all fabricated antimicrobial grafted bilayer microparticles exerted significant antibacterial activity against both strains. The obtained results differ depending on the type of PE bilayer applied. We used acetone to inhibit the growth of bacteria as a negative control. The curcumin loaded unmodified PAA coated microparticles (CCP and CPP) inhibited bacterial growth similar to acetone $(\Phi=8 \mathrm{~mm})$, while microparticles coated with 1-4 polyelectrolytes as the outer layer exerted a stronger effect on both tested bacteria strains $(\Phi=11-20 \mathrm{~mm})$. Therefore the increase of the antibacterial effect cannot be just associated with the CUR release, but some synergistic effect of polyelectrolyte coating and curcumin is possible. A larger zone of growth inhibition was observed for S. aureus ( $\Phi=11-20 \mathrm{~mm}$ ) than for $S$. marcescens $(\Phi=11-12 \mathrm{~mm})$, similar to the antibacterial activity of the PEs discussed above. Interestingly, in the case of CHIT system microcapsules, the diameter of the CC3 and CC4 inhibition zones against S. aureus were 2-3 $\mathrm{mm}$ wider than of the CC1 and CC2.

Similarly, the zone of inhibition against S. marcescens of CC3 and CC4 was $1 \mathrm{~mm}$ wider than of $\mathrm{CC} 1$ and $\mathrm{CC} 2$. That suggests that $\mathrm{CC} 3$ and $\mathrm{CC} 4$ showed greater antimicrobial efficacy than $\mathrm{CC} 1$ and $\mathrm{CC} 2$ oppositely to functionalised polyelectrolytes in aqueous solutions. These findings are in good agreement with the QCM-D results and the CUR release studies showing that the functionalised PEs $\mathbf{3}$ and $\mathbf{4}$ form a "loose" structure as the outer layer of the microcapsules and that the quaternary ammonium moieties are preferably exposed to effective interactions with the cell walls. On the other hand, positively charged units of decorated PEs $\mathbf{1}$ and $\mathbf{2}$ structures, which form more compact layers, are less accessible to bacterial cells. In the case of the PAH system microcarriers, the results slightly differed from those of the studied microparticles of the CHIT system. Their activity against $S$. aureus resulted in the inhibition zones: $\Phi=13 \mathrm{~mm}$ for CP1 and $\Phi=11 \mathrm{~mm}$ for CP2, while $\Phi=15 \mathrm{~mm}$ for CP3 and $\Phi=12 \mathrm{~mm}$ for CP4. The strain of $S$. marcescens strain turned out to be more resistant to these microparticles $(\Phi=12 \mathrm{~mm})$ than $S$. aureus. The obtained results indicate that the functionalised CHIT system microparticles generated wider zones of inhibition for S. aureus than those of the PAH system, while for S. marcescens, similar antibacterial properties of both systems were observed. The stronger antibacterial effect of the CHIT system microparticles can result from the presence of CHIT in their structure, which has antibacterial activity on its own [52].

The above studies demonstrated that microcarriers decorated with the antibacterially functionalised PAA (A-QAS-Pes) show a stronger inhibitory effect on bacterial growth in comparison to polymers in aqueous solutions. That can be explained by the chemical structure of PEs and their hydrophobic chains, which partially hinder the exposure of quaternary ammonium moieties in the solution. Moreover, applying the A-QAS-PEs on the microparticle surface is likely to physically disrupt the polymer backbone and expose the terminal cationic moieties responsible for antimicrobial activity in the environment. 
Table 5. Diameters of inhibition zone $(\mathrm{mm})$ for A-QAS-PEs and microcarriers coated with A-QAS-PEs against S. aureus and S. marcescens.

\begin{tabular}{|c|c|c|c|}
\hline & \multirow{2}{*}{ Studied sample } & \multicolumn{2}{|c|}{ Zone of inhibition (mm) } \\
\hline & & S. aureus & S. marcescens \\
\hline \multirow{6}{*}{ 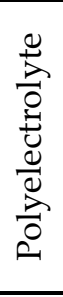 } & control & - & - \\
\hline & PAA & $9 \pm 0.8$ & - \\
\hline & PAA-C $(\mathrm{O}) \mathrm{O}-\left(\mathrm{CH}_{2}\right)_{6}-\mathrm{N}^{+}\left(\mathrm{CH}_{3}\right)_{3}-8 \%$ & $12 \pm 0.6$ & $7 \pm 0.1$ \\
\hline & PAA-C(O)O- $\left(\mathrm{CH}_{2}\right)_{6}-\mathrm{N}^{+}\left(\mathrm{CH}_{3}\right)_{3}-10 \%$ & $12 \pm 0.6$ & $7 \pm 0.1$ \\
\hline & PAA-C $(\mathrm{O}) \mathrm{O}-\left(\mathrm{CH}_{2}\right)_{12}-\mathrm{N}^{+}\left(\mathrm{CH}_{3}\right)_{3}-8 \%$ & $10 \pm 0.6$ & $7 \pm 0.1$ \\
\hline & PAA-C $(\mathrm{O}) \mathrm{O}-\left(\mathrm{CH}_{2}\right)_{12}-\mathrm{N}^{+}\left(\mathrm{CH}_{3}\right)_{3}-14 \%$ & $11 \pm 0.6$ & $7 \pm 0.1$ \\
\hline \multirow{11}{*}{ 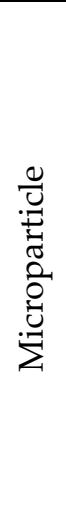 } & control & $8 \pm 0.2$ & $8 \pm 0.3$ \\
\hline & $\mathrm{CCP}$ & $8 \pm 0.3$ & $8 \pm 0.2$ \\
\hline & CC1 & $16 \pm 1.0$ & $12 \pm 0.8$ \\
\hline & $\mathrm{CC} 2$ & $17 \pm 0.5$ & $12 \pm 0.7$ \\
\hline & CC3 & $18 \pm 0.6$ & $11 \pm 0.6$ \\
\hline & CC4 & $20 \pm 0.6$ & $12 \pm 0.8$ \\
\hline & $\mathrm{CPP}$ & $8 \pm 0.4$ & $8 \pm 0.4$ \\
\hline & CP1 & $13 \pm 0.8$ & $12 \pm 0.7$ \\
\hline & $\mathrm{CP} 2$ & $11 \pm 0.6$ & $12 \pm 0.8$ \\
\hline & $\mathrm{CP3}$ & $15 \pm 1.0$ & $12 \pm 0.6$ \\
\hline & $\mathrm{CP} 4$ & $12 \pm 0.6$ & $12 \pm 0.7$ \\
\hline
\end{tabular}

The results are expressed as mean \pm S.D..

(a)

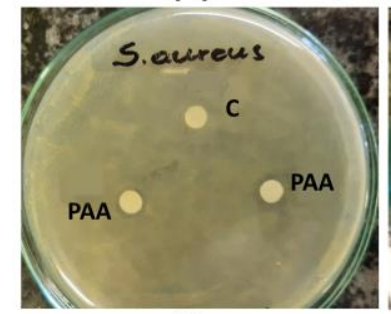

(f)

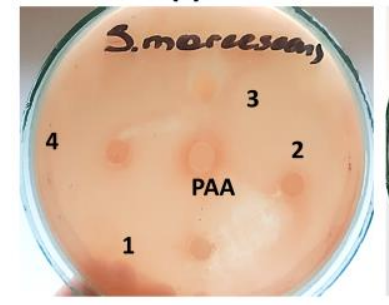

(b)

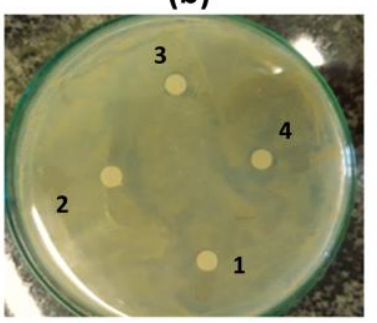

(g)

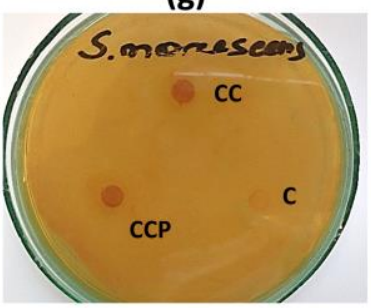

(c)

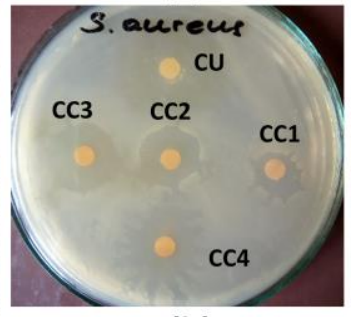

(h)

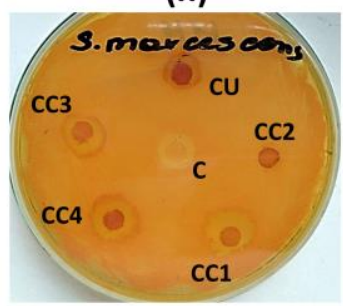

(d)

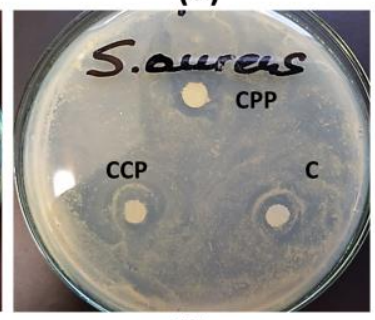

(i)

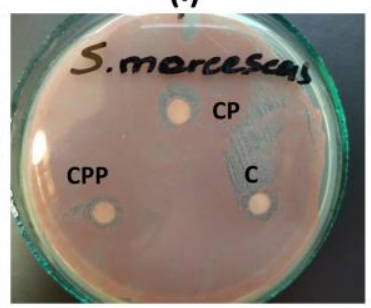

(e)

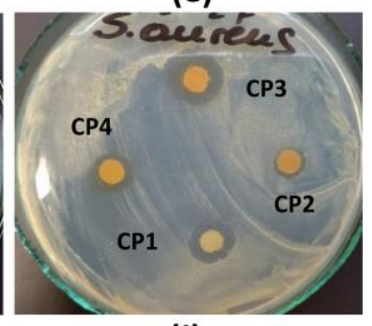

(j)

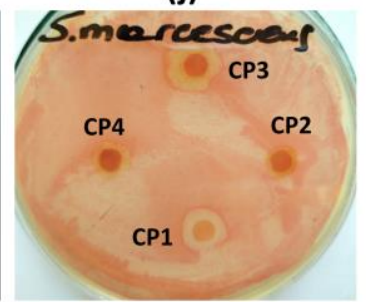

Figure 8. Photographs of sample inhibition zone test plates for PAA (a), decorated PEs 1, 2, 3, 4 (b), CU, CC1, CC2, CC3, CC4 microparticles (c), CCP, CPP microparticles (d), CP1, CP2, CP3, CP4 microparticles (e) against S. aureus and decorated PEs 1, 2, 3, 4 and PAA (f), CC, CCP microparticles (g), CU, CC1, CC2, CC3, CC4 microparticles (h), CP, CPP microparticles (i), CP1, CP2, CP3, $\mathrm{CP} 4$ microparticles (j) against $\mathrm{S}$. marcescens. Distilled water or acetone was used as a control, C.

\section{Materials and Methods}

\subsection{Materials}

Poly(acrylic acid) (molecular weight (Mw=100 kDa) (PAA), trimethylamine (TMA), alginic acid sodium salt of medium viscosity (ALG), polyethylene imine (PEI) (Mw=600$1000 \mathrm{kDa})$, poly(allylamine hydrochloride) $(\mathrm{PAH})(\mathrm{Mw}=450 \mathrm{kDa})$, Span 80, Tween 80 and $\mathrm{D}_{2} \mathrm{O}(99.9 \%$ at D) were purchased from Sigma-Aldrich (Poznań, Poland). 12-bromododecan-1-ol (purity $99.13 \%$ ) and 6-bromohexan-1-ol (purity $97.67 \%$ ) were 
obtained from BLD Pharmatech Ltd (Shanghai, China). N,N'-dicyclohexylcarbodiimide (DCC), 4-dimethylaminopyridine (DMAP) and chitosan (CHIT) (Mw=100-300 kDa) were all synthetic grade and purchased from Acros Organics (Geel, Belgium). Curcumin (CUR) was obtained from Archem Sp. z o. o. (Kamieniec Wrocławski, Poland). Nutrient broth and Mueller-Hinton agar were purchased from Biocorp Polska Sp. z o. o. (Warszawa, Poland). Methanol and acetic acid were analytical grade and purchased from P.P.H.' STANLAB' Sp. J. (Lublin, Poland). Calcium chloride, dimethylsulfoxide (DMSO), hexane, and acetone (all chemicals of analytical grade) were obtained from Avantor Performance Materials (Gliwice, Poland).

\subsection{Synthesis of the poly(acrylic acid) containing alkylene quaternary ammonium groupings}

Under Steglich conditions, dodecyl and hexyl modified poly(acrylic acid) with ester linking groups were prepared - the raw material for the synthesis of side chain functionalised polyelectrolytes with antimicrobial moieties. Briefly: $13.89 \mathrm{mmol}$ of carboxylic acid groups in poly(acrylic acid), 12-bromododecan-1-ol (4.17 mmol or $6.25 \mathrm{mmol}$ for $8 \%$ or $14 \%$ substitution, respectively) or 6-bromohexan-1-ol (4.17 mmol or $6.25 \mathrm{mmol}$ for $8 \%$ or $10 \%$ substitution, respectively), an appropriate amount of DCC (5.42 $\mathrm{mmol}$ or 8.13 mmol for $8 \%$ or $14 \%$ substitution for dodecyl functionalized poly(acrylic acid) or 5.42 mmol or $8.13 \mathrm{mmol}$ for $8 \%$ or $10 \%$ substitution for hexyl functionalized poly(acrylic acid), respectively) and a catalytic amount of DMAP were dissolved in $50 \mathrm{ml}$ of DMSO. The mixture was stirred at $22{ }^{\circ} \mathrm{C}$ for $48 \mathrm{~h}$. After reaction completion, $1 \mathrm{ml}$ of distilled water was added to the mixture to decompose unreacted DCC, followed by an additional $2 \mathrm{~h}$ of stirring. The precipitated by-product, dicyclohexylurea (DCU), was removed from the reaction mixture by filtration, followed by solution dialysis with distilled water ( 4 days, $\mathrm{MWCO}=3500$ ). The resulting solution was filtered, and the modified poly(acrylic acid) was isolated by lyophilisation. Next, the synthesised poly(acrylic acid) with an alkyl side chain was coupled with the following antimicrobial groups: dodecyl or hexyl modified poly(acrylic acid) (1.0 g) and sodium hydroxide (4.77 $\mathrm{mmol}$ or $2.97 \mathrm{mmol}$ for substitution of $8 \%$ or $14 \%$ substitution for dodecyl functionalised poly(acrylic acid) or $5.73 \mathrm{mmol}$ or $3.85 \mathrm{mmol}$ for substitution of $8 \%$ or $10 \%$ substitution for hexyl functionalised poly(acrylic acid), respectively) were dissolved separately in methanol. The alcoholic polyelectrolyte solution was neutralised by dropping the methanolic sodium hydroxide solution into the prepared polymeric solution. The reaction mixture was left for $4 \mathrm{~h}$ at $22{ }^{\circ} \mathrm{C}$. Then 10 times the excess of TMA was added to the prepared solution and the whole mixture was left for $48 \mathrm{~h}$ at $4{ }^{\circ} \mathrm{C}$. The organic solvent was removed under reduced pressure to obtain the desired product.

PAA-C(O)O- $\left(\mathrm{CH}_{2}\right)_{6}-\mathrm{N}^{+}\left(\mathrm{CH}_{3}\right)_{3}-8 \%$ : Yield: $48 \%$

FTIR $/ \mathrm{cm}^{-1}$ : $3359(\mathrm{O}-\mathrm{H}$, stretching), $2926(\mathrm{C}-\mathrm{H}$, stretching), $1702(\mathrm{C}=\mathrm{O}$, stretching-ester), 1664 ( $\mathrm{C}=\mathrm{O}$, stretching-carboxylic acid), 1467 (C-N, stretching), 984 (C-O-C, stretching) ${ }^{1} \mathrm{H}$ NMR/ppm, $\mathrm{D}_{2} \mathrm{O}:-\mathrm{CH}(\mathrm{CO}) \mathrm{CH}_{2}-\left(1.10-2.45\right.$, broad m), $-\mathrm{CH}_{2} \mathrm{~N}-(3.60-3.65, \mathrm{~m}),-\mathrm{N}\left(\mathrm{CH}_{3}\right)_{3}$ $(3.31-3.33, \mathrm{~s})$

PAA-C(O)O- $\left(\mathrm{CH}_{2}\right)_{6}-\mathrm{N}^{+}\left(\mathrm{CH}_{3}\right)_{3}-\mathbf{1 0} \%$ : Yield: $39 \%$

FTIR/ $\mathrm{cm}^{-1}$ : $3365(\mathrm{O}-\mathrm{H}$, stretching), $2924(\mathrm{C}-\mathrm{H}$, stretching), $1703(\mathrm{C}=\mathrm{O}$, stretching-ester), $1666(\mathrm{C}=\mathrm{O}$, stretching-carboxylic acid), $1465(\mathrm{C}-\mathrm{N}$, stretching), 982 (C-O-C, stretching) ${ }^{1} \mathrm{H}$ NMR/ppm, $\mathrm{D}_{2} \mathrm{O}:-\mathrm{CH}(\mathrm{CO}) \mathrm{CH}_{2}-(1.15-2.40$, broad $\mathrm{m}),-\mathrm{CH}_{2} \mathrm{~N}-(3.60-3.65, \mathrm{~m}),-\mathrm{N}\left(\mathrm{CH}_{3}\right)_{3}$ $(3.32-3.35, \mathrm{~s})$

PAA-C(O)O- $\left(\mathrm{CH}_{2}\right)_{12}-\mathrm{N}+\left(\mathrm{CH}_{3}\right)_{3}-8 \%$ : Yield: $55 \%$

FTIR/ $\mathrm{cm}^{-1}: 3327$ (O-H, stretching), 2924 (C-H, stretching), 1708 (C=O, stretching-ester), $1654(\mathrm{C}=\mathrm{O}$, stretching-carboxylic acid), 1477 (C-N, stretching), 985 (C-O-C, stretching)

${ }^{1} \mathrm{H} \mathrm{NMR} / \mathrm{ppm}, \mathrm{D}_{2} \mathrm{O}:-\mathrm{CH}(\mathrm{CO}) \mathrm{CH}_{2}-(1.20-2.30$, broad $\mathrm{m}),-\mathrm{CH}_{2} \mathrm{~N}-(3.56-3.61, \mathrm{~m}),-\mathrm{N}\left(\mathrm{CH}_{3}\right)_{3}$ (3.25-3.30, s)

PAA-C(O)O- $\left(\mathrm{CH}_{2}\right)_{12}-\mathrm{N}^{+}\left(\mathrm{CH}_{3}\right)_{3}-\mathbf{1 4} \%$ : Yield: $46 \%$

FTIR/ $\mathrm{cm}^{-1}$ : $3325(\mathrm{O}-\mathrm{H}$, stretching), $2922(\mathrm{C}-\mathrm{H}$, stretching), 1706 (C=O, stretching-ester), 1643 ( $\mathrm{C}=\mathrm{O}$, stretching-carboxylic acid), 1478 (C-N, stretching), 984 (C-O-C, stretching) 
${ }^{1} \mathrm{H}$ NMR/ppm, $\mathrm{D}_{2} \mathrm{O}:-\mathrm{CH}(\mathrm{CO}) \mathrm{CH}_{2}-\left(1.25-2.40\right.$, broad m), $-\mathrm{CH}_{2} \mathrm{~N}-(3.52-3.59, \mathrm{~m}),-\mathrm{N}\left(\mathrm{CH}_{3}\right)_{3}$ $(3.24-3.31, \mathrm{~s})$

\section{3. ${ }^{1} H$ NMR spectroscopic analysis}

The new A-QAS-PEs were characterised by ${ }^{1} \mathrm{H}$ NMR spectroscopy. The spectra were recorded using the Bruker AMX500 apparatus (Bruker, Billerica, MA, USA) at $25^{\circ} \mathrm{C}$. Before measurements, the A-QAS-PEs were dissolved in $\mathrm{D}_{2} \mathrm{O}$ (concentration 1-3\%) and left overnight at room temperature. Chemical shifts are given in ppm $(\delta$ scale) and refer to HDO signal $(4.71 \mathrm{ppm})$ with a spectral resolution of at least $0.730 \mathrm{~Hz}$.

\subsection{FTIR spectroscopic analysis}

Fourier transform infrared (FTIR) spectra of A-QAS-PEs and fabricated microparticles were recorded with a spectrophotometer (IR Spirit, Shimadzu Corporation, Japan) equipped with a diamond crystal attenuated total reflection (ATR) accessory. Spectra were recorded in the range of $4000-400 \mathrm{~cm}^{-1}$, with a resolution of $2 \mathrm{~cm}^{-1}$ and 64 scans.

\subsection{Formation of microspheres}

An emulsion method was applied to prepare ALG-based microspheres encapsulating CUR, as previously described [25], with slight modifications. First, CUR was dispersed in a $1.5 \%$ ALG aqueous solution $(1: 100 \mathrm{w} / \mathrm{v})$ containing $1 \%(\mathrm{w} / \mathrm{v})$ Tween 80 . The prepared solution was transferred to a round bottom reactor with hexane $(1: 4, \mathrm{v} / \mathrm{v})$ containing 1\% Span $80(\mathrm{w} / \mathrm{v})$ and emulsified at $900 \mathrm{rpm}$ for $10 \mathrm{~min}$ to receive the first emulsion. Then, $0.6 \mathrm{M}$ calcium chloride aqueous solution with $1 \%(\mathrm{w} / \mathrm{v})$ Tween 80 was homogenised with hexane containing $1 \%$ Span $80(\mathrm{w} / \mathrm{v})(2: 3, \mathrm{v} / \mathrm{v})$ and the second emulsion was added dropwise to the first emulsion and stirred for $60 \mathrm{~min}$. After complete crosslinking, ALG microbeads were withdrawn from the mixture, washed, and dried.

\subsection{Layer-by-layer microparticles coating}

Microcapsules were formed by the LbL approach using CHIT or PAH as the polycation and PAA or PAA-C $(\mathrm{O}) \mathrm{O}-\left(\mathrm{CH}_{2}\right)_{n}-\mathrm{N}^{+}\left(\mathrm{CH}_{3}\right)_{3}(\mathrm{~m})$ as the polyanion. To obtain the first coating layer, the microspheres were dispersed in $0.4 \%$ CHIT solution (dissolved in $2 \%$ acetic acid) or $0.1 \% \mathrm{PAH}$ aqueous solution by $3 \mathrm{~min}$ sonication (Polsonic) and stirred for $15 \mathrm{~min}$. To deposit the second coating layer, the microparticles were dispersed by $3 \mathrm{~min}$ sonication in $0.1 \%$ PAA or PAA-C $(\mathrm{O}) \mathrm{O}-\left(\mathrm{CH}_{2}\right)_{\mathrm{n}}-\mathrm{N}^{+}\left(\mathrm{CH}_{3}\right)_{3}(\mathrm{~m})$ aqueous solution $(\mathrm{pH}=5)$ and then gently stirred for $10 \mathrm{~min}$. After each polyelectrolyte deposition step, the microcapsules were filtered and washed with distilled water. The microparticles were finally collected, dried, and stored at ambient temperature.

\subsection{Morphology and particle size}

The surface morphology of the fabricated microparticles was examined by scanning electron microscopy (SEM) (JSM-6601LV, JEOL, Japan) at an acceleration voltage of 4 to $13 \mathrm{kV}$. The size of the studied particles was determined using a polarisation microscope (Eclipse TE2000S, Nikon, Japan). The mean diameter of the microparticles was estimated as the mean diameter of at least 100 randomly selected particles. The polydispersity index (PDI) of the size distribution was characterised by the following equation:

$$
P D I=\frac{\sum_{i=1}^{N}\left(x_{i}^{2}\right)}{\bar{x} * \sum_{i=1}^{N} x_{i}},
$$

where $x_{i}$ is the diameter of the microparticles and $\bar{x}$ is the average diameter of the microparticles [53]. The experiments were carried out in triplicate. 


\subsection{Encapsulation efficiency}

To determine the encapsulation efficiency (EE) of the fabricated microparticles, they were first mechanically destroyed and then suspended in acetone for $48 \mathrm{~h}$ at room temperature with stirring. Then the amount of CUR extracted from the particles was estimated using UV-Vis spectrophotometry $(\lambda=419 \mathrm{~nm})$ (U-2900, Hitachi, Japan) and the appropriate calibration curve. The encapsulation efficiency was calculated using the following equation:

$$
E E=\frac{m_{e}}{m_{i}} * 100 \%,
$$

where $m_{e}$ is the mass of the CUR encapsulated in microparticles and $m_{i}$ is the initial mass of CUR used for encapsulation. Experiments were performed in triplicate.

\subsection{QCM-D analysis}

The multilayer buildup was analysed in situ with quartz crystal microbalance with dissipation monitoring (QSense Biolin Scientific, Sweden). A 14mm diameter piezoelectric quartz crystal covered on both sides with gold electrodes was used as a solid substrate for multilayer growth. Before use, the sensors were cleaned in an ultrasound bath using a $2 \%$ Hellmanex III solution (Hellma, Germany). The sensors were excited at their fundamental resonance frequency $(4.95 \mathrm{MHz})$ and at the $3^{\text {rd }}, 5^{\text {th }}, 7^{\text {th }}, 9$ th, and $11^{\text {th }}$ overtones. The changes in frequency $(\Delta \mathrm{f})$ and dissipation $(\Delta \mathrm{D})$ of all overtones as a function of time were monitored. The QCM-D experiments were performed at room temperature with a $0.150 \mathrm{ml} / \mathrm{min}$ flow rate. Measurements were started with distilled water to establish the baseline frequency of the sensor. Subsequently, the multilayer films were built by sequentially depositing the polyelectrolytes on the crystals. The initial layer of positively charged PEI $(0.05 \%, w / v)$ was adsorbed as an anchor layer on the negatively charged gold sensors. After that, a curcumin-loaded alginate mixture (CUR-ALG) $(0.15 \%, \mathrm{w} / \mathrm{v})$ was deposited as a first layer and crosslinked with calcium ions to mimic the microparticle core. Then, CHIT $(0.04 \%$, w/v) or PAH and A-QAS-PE $(0.05 \%$, w/v) were adsorbed on the sensors to mimic microparticle coatings. After the deposition of each polyelectrolyte, the excess of unadsorbed molecules was rinsed with distilled water. The S1 Smartfit or B1 Broadfit models (QSense Dfind) were applied to estimate the soft layers' parameters. They were established as the best-fit parameters for the frequency and dissipation values at the plateau reached at the rinsing step. For rigid films $\left(\Delta \mathrm{D}<1 \times 10^{-6}\right.$ per $\left.10 \mathrm{~Hz}\right)$ [34], the mass of the adsorbed layer was calculated from the Sauerbrey equation shown below:

$$
\Delta m=-C \frac{\Delta f}{n}
$$

where $C$ is the crystal constant equal to $17.7 \mathrm{ng} / \mathrm{cm}^{2} \mathrm{~Hz}$ and $n$ is the overtone number.

\subsection{Zeta potential}

The zeta potential measurements were conducted using LDE (Laser Doppler Electrophoresis). The experiments were performed using the Zetasizer Nano Series (Malvern Instruments, Malvern, United Kingdom). The aqueous solutions of CHIT $(0.04 \%$, w/v) or $\mathrm{PAH}$, unmodified PAA and A-QAS-PE $(0.05 \%, \mathrm{w} / \mathrm{v})$ were used without $\mathrm{pH}$ adjustment. Each value was obtained as an average of three subsequent runs of the instrument with at least 3 measurements. All experiments were performed at $22^{\circ} \mathrm{C}$.

\subsection{Spectroscopic ellipsometry analysis}

Spectroscopic ellipsometry was applied to measure the thickness of dry PE films. Before forming multilayer films, the $1 \times 1 \mathrm{~cm}$ silicon wafers were washed with the piranha solution, rinsed with distilled water, boiled four times in distilled water, and stream-dried with air. After that, PEI $(0.05 \%, \mathrm{w} / \mathrm{v})$ was adsorbed onto the wafer as the 
precursor film was adsorbed onto the wafer. Next, CUR/ALG $(0.15 \%$, w/v) was deposited on a PEI film as the base layer, followed by crosslinking of ALG with calcium ions. Subsequently, CHIT $(0.04 \%, \mathrm{w} / \mathrm{v})$ or PAH $(0.05 \%$, w $/ \mathrm{v})$ was adsorbed on the ALG layer, and A-QAS-PE $(0.05 \%, w / v)$ was deposited as the final layer. Each PE adsorption lasts $20 \mathrm{~min}$, followed by washing with distilled water to remove excess of unadsorbed PE. Finally, the samples were dried with air. The thickness and optical parameters of the films were estimated by fitting the Cauchy optical model to the measured wavelength dependence of the ellipsometric angles $\Delta$ and $\Psi$ as described previously [49].

\subsection{Release profiles}

The kinetics of CUR release from the fabricated microparticles was studied in phosphate buffer saline (PBS) $(\mathrm{pH}=7.4)$ at $37^{\circ} \mathrm{C}$ for $24 \mathrm{~h}$. Initially, microcarriers were soaked in PBS $(1: 40, \mathrm{w} / \mathrm{v})$ and transferred into a cellulose bag. The bag was then closed, immersed in $8 \mathrm{ml}$ of PBS medium, and stirred (1000 rpm) to initiate the release of CUR. At predetermined time intervals, the release medium was withdrawn and replaced with the same volume of fresh medium. Finally, the amount of CUR was estimated by spectrophotometry $(\lambda=419 \mathrm{~nm})(\mathrm{U}-2900$, Hitachi, Japan) and an appropriate calibration curve. The results obtained were expressed as the percentage of cumulative CUR release over time. Experiments were performed in triplicate. The CUR release profiles of microparticles were described using the following hybrid model [41]:

$$
\frac{M_{t}}{M_{\infty}}=\frac{M_{1}}{M_{\infty}}\left(1-e^{\left(-k_{1} t\right)}\right)+k_{2} t^{n_{1}}
$$

where: $\mathrm{M}$ is the amount of CUR released during the burst phase; $\mathrm{k}_{1}$ is a first-order rate constant and $\mathrm{k}_{2}$ is a Korsmeyer-Peppas release constant; $\mathrm{n}$ is the release exponent. The model was fitted to the experimental data using OriginPro 9.0 software (OriginLab Corporation, USA).

\subsection{Antimicrobial activity - disc diffusion method}

The antimicrobial activity of the A-QAS-PEs and the microparticles coated with A-QAS-PEs was tested against the Gram-positive bacterial strain (Staphylococcus aureus PCM 2054) and the Gram-negative strain (Serratia marcescens PCM 549) using the disc diffusion method. The bacterial strains were cultivated in nutrient broth for $24 \mathrm{~h}$ and each bacterial suspension used as inoculum was adjusted to $0.5 \mathrm{McF}$ arland standard. The Petri dishes were dried for $10 \mathrm{~min}$ before using in the antimicrobial activity test. Sterile filter paper discs (6 mm diameter) were impregnated with a $10 \mu \mathrm{l}$ solution of polyelectrolytes or microparticles suspension $(C=10 \mathrm{mg} / \mathrm{ml})$. The discs were placed on Mueller-Hinton agar plates inoculated with the bacteria. Sterile double-distilled water or acetone was used as a negative control for polyelectrolytes or microparticles, respectively. All plates were left for $15 \mathrm{~min}$ at room temperature to allow the diffusion. The plates were then incubated at $37^{\circ} \mathrm{C}$ for $24 \mathrm{~h}$. After incubation, the diameters of the inhibition zones formed around the discs were measured. Experiments were performed in triplicate.

\section{Conclusions}

We have successfully engineered and characterised four types of new antimicrobial grafted polyelectrolytes, i.e., alkylene quaternary ammonium salt functionalised poly(acrylic acid) (PAA) derivatives, which were found to be suitable to coat as the outer layer a series of curcumin (CUR)-loaded hydrogel microparticles via the layer-by-layer (LbL) technique. The fabricated bilayered microcarriers consisted of sodium alginate (ALG) as the core component, biocompatible/biodegradable chitosan (CHIT) or synthetic poly(allylamine hydrochloride) (PAH) provided the first coating layer and a newly synthesised antimicrobial decorated PAA - deposited as the outer layer - provided the functional coating. Differences in their chemical structure have influenced their physicochemical and biological properties. In particular, the antimicrobial grafted PAAs could 
form films with different viscoelastic properties that directly resulted from their hydrophobicity. All fabricated bilayer CUR-loaded microcarriers, coated by alkylene quaternary ammonium salt grafted PAAs, showed stronger antibacterial activity against $\mathrm{S}$. aureus and S. marcescens than the antimicrobial decorated PAAs on their own. We also observed that the release of CUR from the functionalised microcapsules could be controlled by the type of the new PE used as an outer layer.

Therefore, modification of the microcarrier surface with PEs containing cationic moieties made it possible to fabricate new microsystems with the desirable antimicrobial function and, additionally, they provided desirable possibilities of the payload controlled release. The effective antimicrobial activity and drug release features of the designed microsystems open a new path for developing microcarriers with improved therapeutic applications, e.g., in the treatment of bacterial infectious diseases. Our findings could constitute the guidance for future new, improved alkylene quaternary ammonium salt grafted polyelectrolytes (A-QAS-PEs) - products comprising even higher degrees of substitution for quaternary ammonium groups - with plenty of tailored applications in numerous fields.

Supplementary Materials: The following are available online, Figure S1: FTIR spectra of CUR-loaded microparticles decorated with A-QAS-PEs: CHIT system (a) and PAH system (b); Figure S2: FTIR spectra of CUR, CU, CC, and CP; Figure S3: Adsorption kinetic measurements of polyelectrolyte multilayers monitored by QCM-D: (a) PEI/CUR/ALG/CHIT/1; (b) $\mathrm{PEI} / \mathrm{CUR} / \mathrm{ALG} / \mathrm{CHIT} / 2 ; \quad$ (c) $\quad \mathrm{PEI} / \mathrm{CUR} / \mathrm{ALG} / \mathrm{CHIT} / 3 ; \quad$ (d) $\quad \mathrm{PEI} / \mathrm{CUR} / \mathrm{ALG} / \mathrm{CHIT} / 4 ; \quad$ (e) PEI/CUR/ALG/CHIT/PAA; (f) PEI/CUR/ALG/PAH/PAA; (g) PEI/CUR/ALG/PAH/1; (h) PEI/CUR/ALG/PAH/2; (i) PEI/CUR/ALG/PAH/3; (j) PEI/CUR/ALG/PAH/4. Blue lines illustrate frequency shifts $(\Delta \mathrm{f})$, while red lines illustrate dissipation shifts $(\Delta \mathrm{D})$ of polyelectrolyte multilayers. Resonance frequency variations and dissipation variations are recorded as functions of time; Figure S4: CUR release profiles from CU (squares), CC (circles), and CP (triangles) microparticles. The lines correspond to the fitting curves of the hybrid model to the payload release profiles; Table S1: Film thickness characterisation by spectroscopic ellipsometry.

Author Contributions: Conceptualisation, K.A.W. and W.S.; methodology, W.S., M.T.M., Ł.L. L.S.W. and E.Z.; software, W.S.; validation, W.S., M.T.M., Ł.L. L.S.W. and E.Z.; formal analysis, W.S., Ł.L, M.T.M. and L.S.W; investigation, W.S., L.S.W and E.Z; resources, K.A.W. and P.W.; data curation, W.S. and M.T.M.; writing-original draft preparation, W.S.; writing - review and editing, M.T.M., Ł.L., L.S.W., E.Z., K.A.W. and P.W.; visualisation, W.S.; supervision, K.A.W and P.W.; project administration, K.A.W. and P.W. All authors have read and agreed to the published version of the manuscript.

Funding: This research was financed by National Science Centre, Poland within the OPUS program (2017/25/B/ST4/02450) and by a statutory activity subsidy from the Polish Ministry of Science and Higher Education for the Faculty of Chemistry of the Wrocław University of Science and Technology and the Jerzy Haber Institute of Catalysis and Surface Chemistry, Polish Academy of Sciences Kraków.

Institutional Review Board Statement: Not applicable.

Informed Consent Statement: Not applicable.

Data Availability Statement: The data presented in this study are available within the article.

Conflicts of Interest: The authors declare no conflict of interest.

Sample Availability: Samples of the polyelectrolytes are available from the authors.

\section{References}

1. Bansal, R.; Pathak, R.; Kumar, B.; Gautam, H. K.; Kumar, P. Enhanced Antimicrobial Activity of Amphiphilic Cationic Polymers against a Broad Range of Bacterial Strains and Skin Microbes. Colloid and Polymer Science, 2017,295 (7), 1177-1185. https://doi.org/10.1007/s00396-017-4106-9.

2. Villalobos, V.; Leiva, Á.; Ríos, H. E.; Pavez, J.; Silva, C. P.; Ahmar, M.; Queneau, Y.; Blamey, J. M.; Chávez, F. P.; Urzúa, M. D. Inhibiting Pathogen Surface Adherence by Multilayer Polyelectrolyte Films Functionalized with Glucofuranose Derivatives. ACS Applied Materials and Interfaces, 2018, 10 (33), 28147-28158. https://doi.org/10.1021/acsami.8b03605. 
3. Al-Awady, M. J.; Fauchet, A.; Greenway, G. M.; Paunov, V. N. Enhanced Antimicrobial Effect of Berberine in Nanogel Carriers with Cationic Surface Functionality. Journal of Materials Chemistry B, 2017, 5 (38), 7885-7897. https://doi.org/10.1039/c7tb02262j.

4. Ivanova, A.; Ivanova, K.; Hoyo, J.; Heinze, T.; Sanchez-Gomez, S.; Tzanov, T. Layer-By-Layer Decorated Nanoparticles with Tunable Antibacterial and Antibiofilm Properties against Both Gram-Positive and Gram-Negative Bacteria. ACS Applied Materials and Interfaces, 2018, 10 (4), 3314-3323. https://doi.org/10.1021/acsami.7b16508.

5. Decher, G; Schlenoff, JB. Multilayer Thin Films: Sequential Assembly of Nanocomposite Materials: Second Edition. vol. 1-2. Weinheim, Germany: Wiley-VCH Verlag GmbH \& Co. KGaA; 2012. https://doi.org/10.1002/9783527646746.

6. Wurster, E.C.; Elbakry, A.; Göpferich, A.; Breunig, M. Layer-by-Layer Assembled Gold Nanoparticles for the Delivery of Nucleic Acids. Nanotechnology for Nucleic Acid Delivery, 2013, 948, 171-182. https://doi.org/10.1007/978-1-62703-140-0_12

7. Lu, Y.; Wu, Y.; Liang, J.; Libera, M. R.; Sukhishvili, S. A. Self-Defensive Antibacterial Layer-by-Layer Hydrogel Coatings with PH-Triggered Hydrophobicity. Biomaterials, 2015, 45, 64-71. https://doi.org/10.1016/j.biomaterials.2014.12.048.

8. Jin, Y.; Zhou, Q.; Li, Z.; Yang, Z.; Fan, H. J. S. Calcium-Cross Linked Polysaccharide Microcapsules for Controlled Release and Antimicrobial Applications. Colloids and Surfaces A: Physicochemical and Engineering Aspects, $2020,600$. https://doi.org/10.1016/j.colsurfa.2020.125025.

9. Milinković Budinčić, J.; Petrović, L.; Đekić, L.; Fraj, J.; Bučko, S.; Katona, J.; Spasojević, L. Study of vitamin E microencapsulation and controlled release from chitosan/sodium lauryl ether sulfate microcapsules. Carbohydrate Polymers, 2021, $251,116988$. https://doi.org/10.1016/j.carbpol.2020.116988

10. Iqbal, M. H.; Schroder, A.; Kerdjoudj, H.; Njel, C.; Senger, B.; Ball, V.; Meyer, F.; Boulmedais, F. Effect of the Buffer on the Buildup and Stability of Tannic Acid/Collagen Multilayer Films Applied as Antibacterial Coatings. ACS Applied Materials and Interfaces, 2020, 12 (20), 22601-22612. https://doi.org/10.1021/acsami.0c04475.

11. Kougia, E.; Tselepi, M.; Vasilopoulos, G.; Lainioti, G. C.; Koromilas, N. D.; Druvari, D.; Bokias, G.; Vantarakis, A.; Kallitsis, J. K.; McPhee, D. J. Evaluation of Antimicrobial Efficiency of New Polymers Comprised by Covalently Attached and/or Electrostatically Bound Bacteriostatic Species, Based on Quaternary Ammonium Compounds. Molecules, 2015, 20 (12), $21313-21327$. https://doi.org/10.3390/molecules201219768.

12. Kiss, É.; Heine, E. T.; Hill, K.; He, Y. C.; Keusgen, N.; Pénzes, C. B.; Schnöller, D.; Gyulai, G. A.; Mendrek, A.; Keul, H.; et al. Membrane Affinity and Antibacterial Properties of Cationic Polyelectrolytes with Different Hydrophobicity. Macromolecular Bioscience, 2012, 12 (9), 1181-1189. https://doi.org/10.1002/mabi.201200078.

13. Farah, S.; Aviv, O.; Laout, N.; Ratner, S.; Beyth, N.; Domb, A. J. Quaternary Ammonium Poly(Diethylaminoethyl Methacrylate) Possessing Antimicrobial Activity. Colloids and Surfaces B: Biointerfaces, 2015, 128, 608-613. https://doi.org/10.1016/j.colsurfb.2015.01.051.

14. Druvari, D.; Koromilas, N. D.; Lainioti, G. C.; Bokias, G.; Vasilopoulos, G.; Vantarakis, A.; Baras, I.; Dourala, N.; Kallitsis, J. K. Polymeric Quaternary Ammonium-Containing Coatings with Potential Dual Contact-Based and Release-Based Antimicrobial Activity. ACS Applied Materials and Interfaces, 2016, 8 (51), 35593-35605. https://doi.org/10.1021/acsami.6b14463.

15. Olea, A. F. Hydrophobic Polyelectrolytes. In Ionic Interactions in Natural and Synthetic Macromolecules; John Wiley and Sons, 2012; pp 211-233. https://doi.org/10.1002/9781118165850.ch7.

16. Sun, L.; Ma, S.; Wang, C.; Chi, Y.; Dong, J. Supramolecular Self-Assembly of a Polyelectrolyte Chain Based on Step-Growth Polymerization of Hydrophobic and Hydrophilic Monomers. RSC Advances, 2017, 7 (83), 52832-52840. https://doi.org/10.1039/c7ra09205a.

17. Aricov, L.; Petkova, H.; Arabadzhieva, D.; Iovescu, A.; Mileva, E.; Khristov, K.; Stinga, G.; Mihailescu, C. F.; Anghel, D. F.; Todorov, R. Aqueous Solutions of Associative Poly(Acrylates): Bulk and Interfacial Properties. Colloids and Surfaces A: Physicochemical and Engineering Aspects, 2016, 505, 138-149. https://doi.org/10.1016/j.colsurfa.2016.02.018.

18. Janovák, L.; Turcsányi, Â.; Bozó, É.; Deák, Á.; Mérai, L.; Sebők, D.; Juhász, Á.; Csapó, E.; Abdelghafour, M. M.; Farkas, E.; et al. Preparation of Novel Tissue Acidosis-Responsive Chitosan Drug Nanoparticles: Characterization and in Vitro Release Properties of Ca2+ Channel Blocker Nimodipine Drug Molecules. European Journal of Pharmaceutical Sciences, 2018, 123, 79-88. https://doi.org/10.1016/j.ejps.2018.07.031.

19. Lamch, L.; Ronka, S.; Moszynśka, I.; Warszynśki, P.; Wilk, K. A. Hydrophobically Functionalized Poly(Acrylic Acid) Comprising the Ester-Type Labile Spacer: Synthesis and Self-Organisation in Water. Polymers, 2020, 12 (5). https://doi.org/10.3390/POLYM12051185.

20. Lamch, Ł.; Ronka, S.; Warszyński, P.; Wilk, K. A. NMR Studies of Self-Organization Behavior of Hydrophobically Functionalized Poly(4-Styrenosulfonic-Co-Maleic Acid) in Aqueous Solution. Journal of Molecular Liquids, $2020,308$. https://doi.org/10.1016/j.molliq.2020.112990.

21. Wawrzyńczyk, D.; Bazylińska, U.; Lamch, Ł.; Kulbacka, J.; Szewczyk, A.; Bednarkiewicz, A.; Wilk, K. A.; Samoć, M. FÖrster Resonance Energy Transfer-Activated Processes in Smart Nanotheranostics Fabricated in a Sustainable Manner. ChemSusChem, 2019, 12 (3), 706-719. https://doi.org/10.1002/cssc.201801441.

22. Belbekhouche, S.; Bousserrhine, N.; Alphonse, V.; Carbonnier, B. From Beta-Cyclodextrin Polyelectrolyte to Layer-by-Layer Self-Assembly Microcapsules: From Inhibition of Bacterial Growth to Bactericidal Effect. Food Hydrocolloids, $2019,95,219-227$. https://doi.org/10.1016/j.foodhyd.2019.04.037.

23. Prasad, S.; Gupta, S. C.; Tyagi, A. K.; Aggarwal, B. B. Curcumin, a Component of Golden Spice: From Bedside to Bench and Back. Biotechnology Advances. Elsevier Inc. 2014, pp 1053-1064. https://doi.org/10.1016/j.biotechadv.2014.04.004. 
24. Mahmood, K.; Zia, K. M.; Zuber, M.; Salman, M.; Anjum, M. N. Recent Developments in Curcumin and Curcumin Based Polymeric Materials for Biomedical Applications: A Review. International Journal of Biological Macromolecules. Elsevier B.V. November 1, 2015, pp 877-890. https://doi.org/10.1016/j.ijbiomac.2015.09.026.

25. Wezgowiec, J.; Tsirigotis-Maniecka, M.; Saczko, J.; Wieckiewicz, M.; Wilk, K. A. Microparticles vs. Macroparticles as Curcumin Delivery Vehicles: Structural Studies and Cytotoxic Effect in Human Adenocarcinoma Cell Line (Lovo). Molecules, 2021, 26 (19). https://doi.org/10.3390/molecules26196056.

26. Szczęsna, W.; Tsirigotis-Maniecka, M.; Szyk-Warszyńska, L.; Balicki, S.; Warszyński, P.; Wilk, K. A. Insight into Multilayered Alginate/Chitosan Microparticles for Oral Administration of Large Cranberry Fruit Extract. European Polymer Journal, 2021, 160. https://doi.org/10.1016/j.eurpolymj.2021.110776.

27. Tsirigotis-Maniecka, M.; Szyk-Warszyńska, L.; Maniecki, Ł.; Szczęsna, W.; Warszyński, P.; Wilk, K. A. Tailoring the Composition of Hydrogel Particles for the Controlled Delivery of Phytopharmaceuticals. European Polymer Journal, $2021,151$. https://doi.org/10.1016/j.eurpolymj.2021.110429.

28. Xue, Y.; Niu, W.; Wang, M.; Chen, M.; Guo, Y.; Lei, B. Engineering a Biodegradable Multifunctional Antibacterial Bioactive Nanosystem for Enhancing Tumor Photothermo-Chemotherapy and Bone Regeneration. ACS Nano, 2020,14 (1), $442-453$. https://doi.org/10.1021/acsnano.9b06145.

29. Özkan, M.; Kumar, Y.; Keser, Y.; Hadi, S. E.; Tuncel, D. Cucurbit[7.Uril-Anchored Porphyrin-Based Multifunctional Molecular Platform for Photodynamic Antimicrobial and Cancer Therapy. ACS Applied Bio Materials, 2019, 2 (11), $4693-4697$. https://doi.org/10.1021/acsabm.9b00763.

30. Lamch, Ł.; Pucek, A.; Kulbacka, J.; Chudy, M.; Jastrzębska, E.; Tokarska, K.; Bułka, M.; Brzózka, Z.; Wilk, K. A. Recent Progress in the Engineering of Multifunctional Colloidal Nanoparticles for Enhanced Photodynamic Therapy and Bioimaging. Advances in Colloid and Interface Science. Elsevier B.V. November 1, 2018, pp 62-81. https://doi.org/10.1016/j.cis.2018.09.002

31. Kurapati, R.; Groth, T. W.; Raichur, A. M. Recent Developments in Layer-by-Layer Technique for Drug Delivery Applications. ACS Applied Bio Materials, 2019, 2 (12), 5512-5527. https://doi.org/10.1021/acsabm.9b00703.

32. Séon, L.; Lavalle, P.; Schaaf, P.; Boulmedais, F. Polyelectrolyte Multilayers: A Versatile Tool for Preparing Antimicrobial Coatings. Langmuir. American Chemical Society October 29, 2015, pp 12856-12872. https://doi.org/10.1021/acs.langmuir.5b02768.

33. Lichter, J. A.; Rubner, M. F. Polyelectrolyte Multilayers with Intrinsic Antimicrobial Functionality: The Importance of Mobile Polycations. Langmuir, 2009, 25 (13), 7686-7694. https://doi.org/10.1021/la900349c.

34. Kruk, T.; Szczepanowicz, K.; Kregiel, D.; Szyk-Warszyńska, L.; Warszyński, P. Nanostructured Multilayer Polyelectrolyte Films with Silver Nanoparticles as Antibacterial Coatings. Colloids and Surfaces B: Biointerfaces, 2016, 137, 158-166. https://doi.org/10.1016/j.colsurfb.2015.06.016.

35. Kim, B. S.; Park, S. W.; Hammond, P. T. Hydrogen-Bonding Layer-by-Layer-Assembled Biodegradable Polymeric Micelles as Drug Delivery Vehicles from Surfaces. ACS Nano, 2008, 2 (2), 386-392. https://doi.org/10.1021/nn700408z.

36. Lichter, J. A.; van Vlietpa, K. J.; Rubner, M. F. Design of Antibacterial Surfaces and Interfaces: Polyelectrolyte Multilayers as a Multifunctional Platform. Macromolecules, 2009, 42 (22), 8573-8586. https://doi.org/10.1021/ma901356s.

37. Siedenbiedel, F.; Tiller, J. C. Antimicrobial Polymers in Solution and on Surfaces: Overview and Functional Principles. Polymers. 2012, pp 46-71. https://doi.org/10.3390/polym4010046.

38. Waschinski, C. J.; Herdes, V.; Schueler, F.; Tiller, J. C. Influence of Satellite Groups on Telechelic Antimicrobial Functions of Polyoxazolines. Macromolecular Bioscience, 2005, 5 (2), 149-156. https://doi.org/10.1002/mabi.200400169.

39. Popescu, I.; Pelin, I. M.; Ailiesei, G. L.; Ichim, D. L.; Suflet, D. M. Amphiphilic Polysaccharide Based on Curdlan: Synthesis and Behaviour in Aqueous Solution. Carbohydrate Polymers, 2019, 224. https://doi.org/10.1016/j.carbpol.2019.115157.

40. Tsirigotis-Maniecka, M.; Lamch, Ł.; Chojnacka, I.; Gancarz, R.; Wilk, K. A. Microencapsulation of Hesperidin in Polyelectrolyte Complex Microbeads: Physico-Chemical Evaluation and Release Behavior. Journal of Food Engineering, 2017, $214,104-116$. https://doi.org/10.1016/j.jfoodeng.2017.06.015.

41. Tsirigotis-Maniecka, M.; Szyk-Warszyńska, L.; Lamch, Ł.; Weżgowiec, J.; Warszyński, P.; Wilk, K. A. Benefits of PH-Responsive Polyelectrolyte Coatings for Carboxymethyl Cellulose-Based Microparticles in the Controlled Release of Esculin. Materials Science and Engineering C, 2021, 118. https://doi.org/10.1016/j.msec.2020.111397.

42. Almeida, E. A. M. S.; Bellettini, I. C.; Garcia, F. P.; Farinácio, M. T.; Nakamura, C. v.; Rubira, A. F.; Martins, A. F.; Muniz, E. C. Curcumin-Loaded Dual PH- and Thermo-Responsive Magnetic Microcarriers Based on Pectin Maleate for Drug Delivery. Carbohydrate Polymers, 2017, 171, 259-266. https://doi.org/10.1016/j.carbpol.2017.05.034.

43. Sarika, P. R.; James, N. R.; Anil kumar, P. R.; Raj, D. K. Preparation, Characterisation and Biological Evaluation of Curcumin Loaded Alginate Aldehyde-Gelatin Nanogels. Materials Science and Engineering C, 2016, 68, $251-257$. https://doi.org/10.1016/j.msec.2016.05.046.

44. Sorita, G. D.; Santamaria-Echart, A.; Gozzo, A. M.; Gonçalves, O. H.; Leimann, F. v.; Bona, E.; Manrique, Y.; Fernandes, I. P. M.; Ferreira, I. C. F. R.; Barreiro, M. F. Lipid Composition Optimization in Spray Congealing Technique and Testing with Curcumin-Loaded Microparticles. Advanced Powder Technology, 2021. https://doi.org/10.1016/j.apt.2021.03.028.

45. Anirudhan, T. S.; Anila, M. M.; Franklin, S. Synthesis Characterization and Biological Evaluation of Alginate Nanoparticle for the Targeted Delivery of Curcumin. Materials Science and Engineering C, 2017, 78, 1125-1134. https://doi.org/10.1016/j.msec.2017.04.116.

46. Sundaramurthy, A.; Sundramoorthy, A. K. Polyelectrolyte Capsules Preloaded with Interconnected Alginate Matrix: An Effective Capsule System for Encapsulation and Release of Macromolecules. International Journal of Biological Macromolecules, 2018, 107, 2251-2261. https://doi.org/10.1016/j.ijbiomac.2017.10.096. 
47. Lawrie, G.; Keen, I.; Drew, B.; Chandler-Temple, A.; Rintoul, L.; Fredericks, P.; Grøndahl, L. Interactions between Alginate and Chitosan Biopolymers Characterised Using FTIR and XPS. Biomacromolecules, 2007, 8 (8), $2533-2541$. https://doi.org/10.1021/bm070014y.

48. Notley, S. M.; Eriksson, M.; Wågberg, L. Visco-Elastic and Adhesive Properties of Adsorbed Polyelectrolyte Multilayers Determined in Situ with QCM-D and AFM Measurements. Journal of Colloid and Interface Science, 2005,292 (1), $29-37$. https://doi.org/10.1016/j.jcis.2005.05.057.

49. Tsirigotis-Maniecka, M.; Szyk-Warszyńska, L.; Michna, A.; Warszyński, P.; Wilk, K. A. Colloidal Characteristics and Functionality of Rationally Designed Esculin-Loaded Hydrogel Microcapsules. Journal of Colloid and In-terface Science, 2018, 530, 444-458. https://doi.org/10.1016/j.jcis.2018.07.006

50. Korsmeyer, R. W.; Gurny, R.; Doelker, E.; Buri, P.; Peppas, N. A. Mechanisms of Solute Release from Porous Hydrophilic Polymers; 1983, 15, 1, 25-35. https://doi.org/10.1016/0378-5173(83)90064-9

51. Uppu, D. S. S. M.; Samaddar, S.; Ghosh, C.; Paramanandham, K.; Shome, B. R.; Haldar, J. Amide Side Chain Amphiphilic Polymers Disrupt Surface Established Bacterial Bio-Films and Protect Mice from Chronic Acinetobacter Baumannii Infection. Biomaterials, 2016, 74, 131-143. https://doi.org/10.1016/j.biomaterials.2015.09.042.

52. Kumorek, M.; Minisy, I. M.; Krunclová, T.; Voršiláková, M.; Venclíková, K.; Chánová, E. M.; Janoušková, O.; Kubies, D. PH-Responsive and Antibacterial Properties of Self-Assembled Multilayer Films Based on Chitosan and Tannic Acid. Materials Science and Engineering C, 2020, 109. https://doi.org/10.1016/j.msec.2019.110493.

53. Tsirigotis-Maniecka, M.; Gancarz, R.; Wilk, K. A. Polysaccharide Hydrogel Particles for Enhanced Delivery of Hesperidin: Fabrication, Characterisation and in Vitro Evaluation. Colloids and Surfaces A: Physicochemical and Engineering Aspects, 2017, 532, 48-56. https://doi.org/10.1016/j.colsurfa.2017.07.001. 